\title{
Aerial Photographs and Satellite Images
}
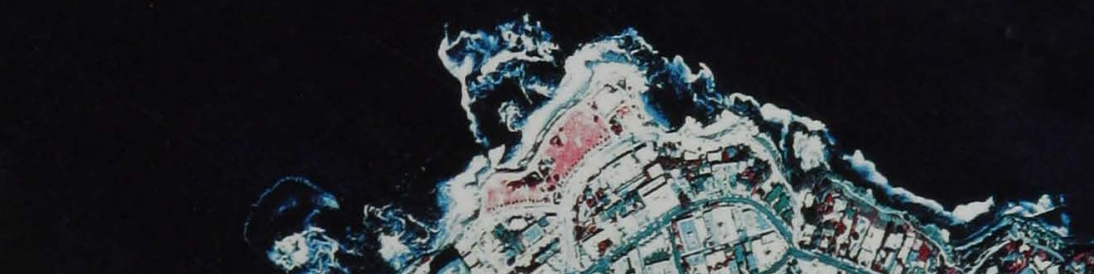

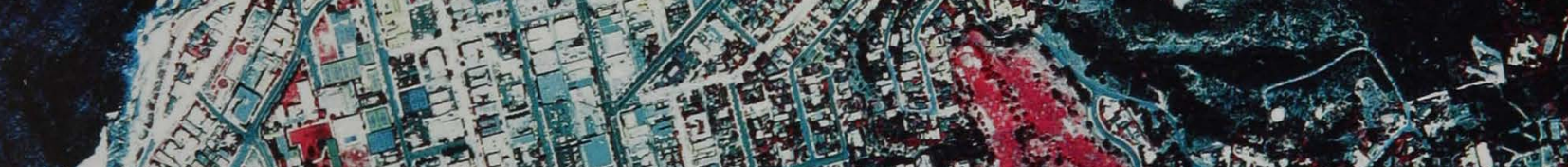
-3.1.

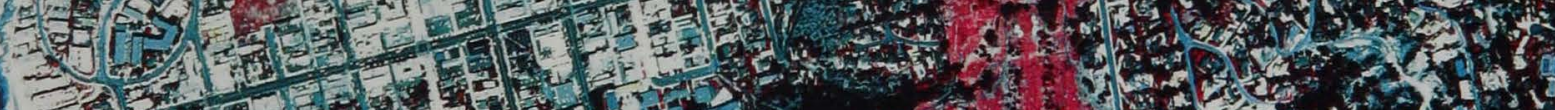
-150 (1) H. (4)

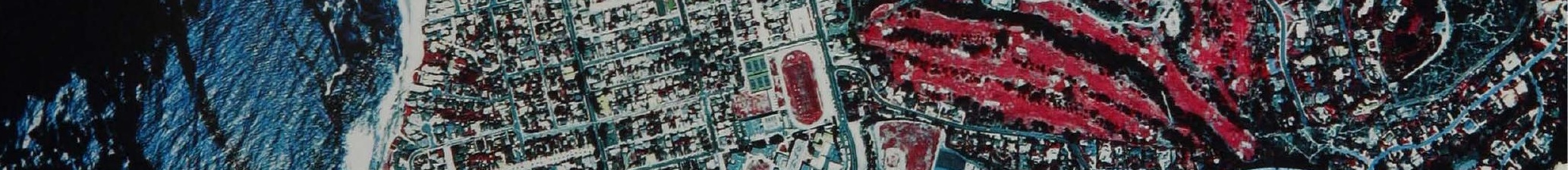

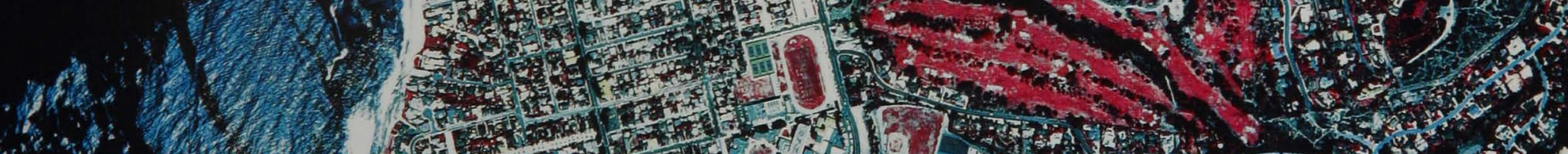

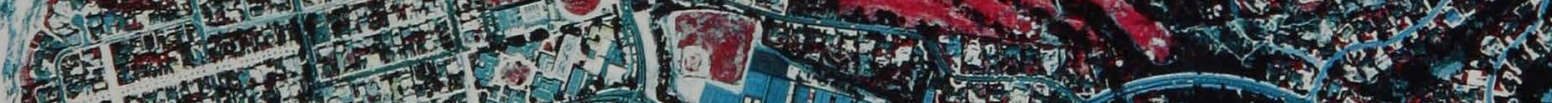

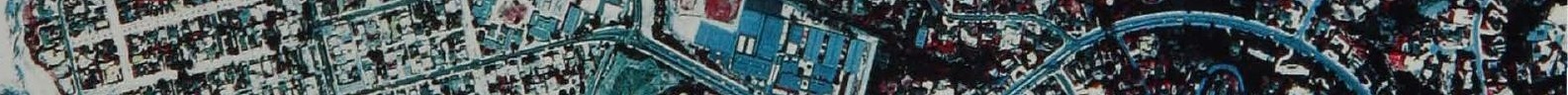
5. 1.

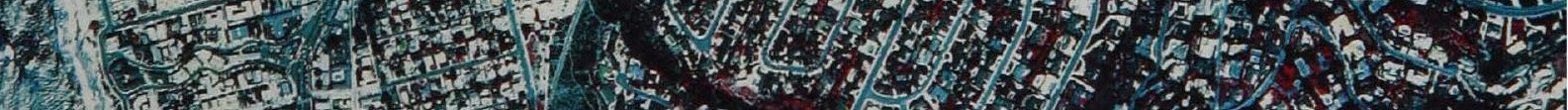
4 (1) 1.t. (7.6.

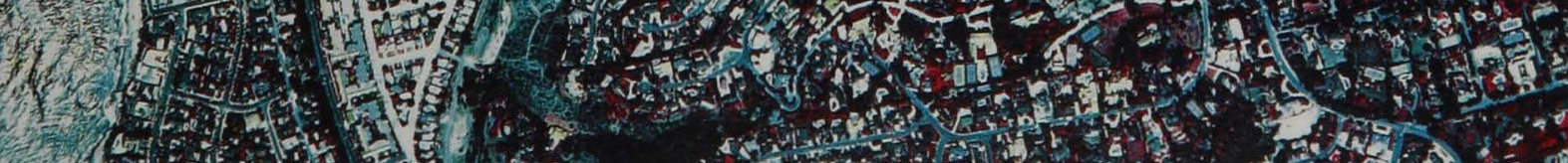
1 (15)

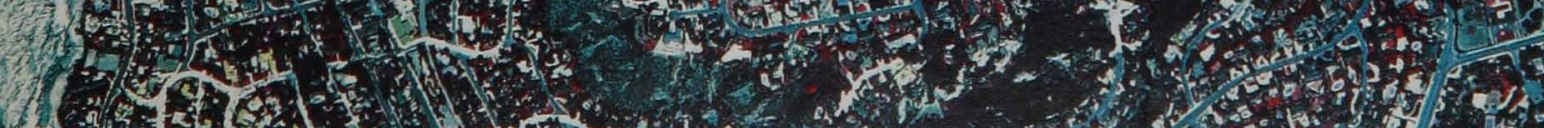

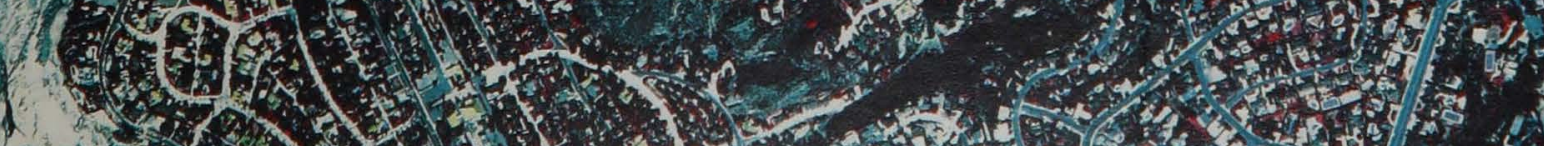

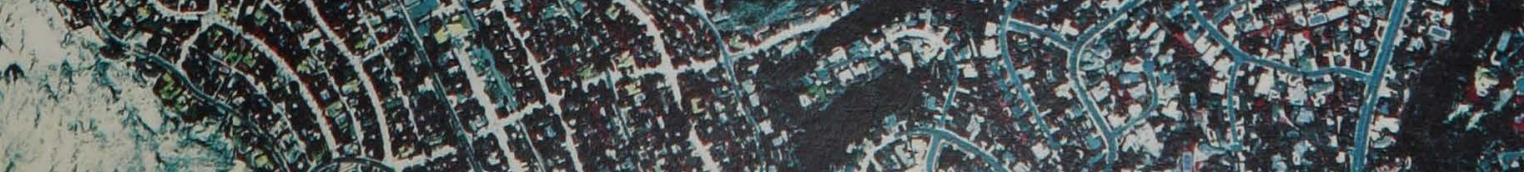





\section{The U.S. Geological Survey and Remote Sensing}

Photographs and other images of the Earth taken from the air and from space show a great deal about the planet's landforms, vegetation, and resources. Aerial and satellite images, known as remotely sensed images, permit accurate mapping of land cover and make landscape features understandable on regional, continental, and even global scales. Transient phenomena, such as seasonal vegetation vigor and contaminant discharges, can be studied by comparing images acquired at different times.

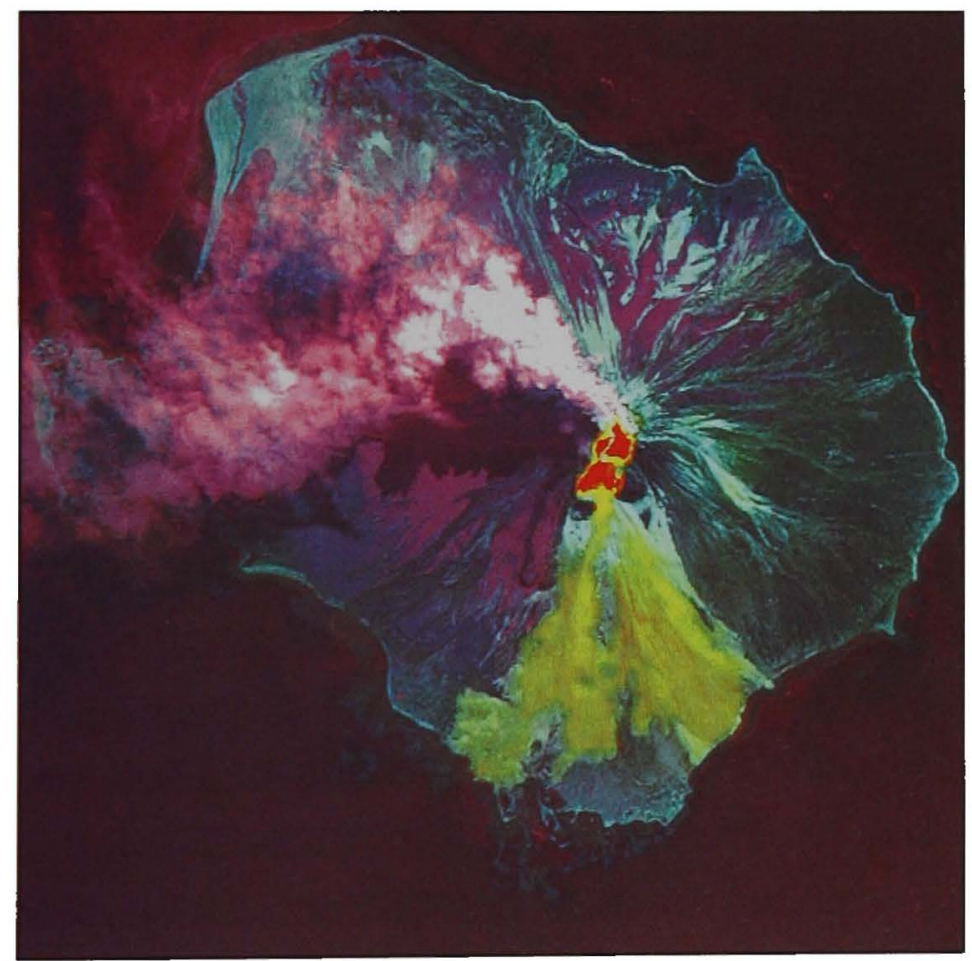

Figure 3: Augustine Volcano, Alaska, Landsat 5 thematic mapper satellite image, April 1986
The U.S. Geological Survey (USGS), which began using aerial photographs for mapping in the 1930's, archives photographs from its mapping projects and from those of some other Federal agencies. In addition, many images from such space programs as Landsat, begun in 1972, are held by the USGS. Most satellite scenes can be obtained only in digital form for use in computer-based image processing and geographic information systems, but in some cases are also available as photographic products.

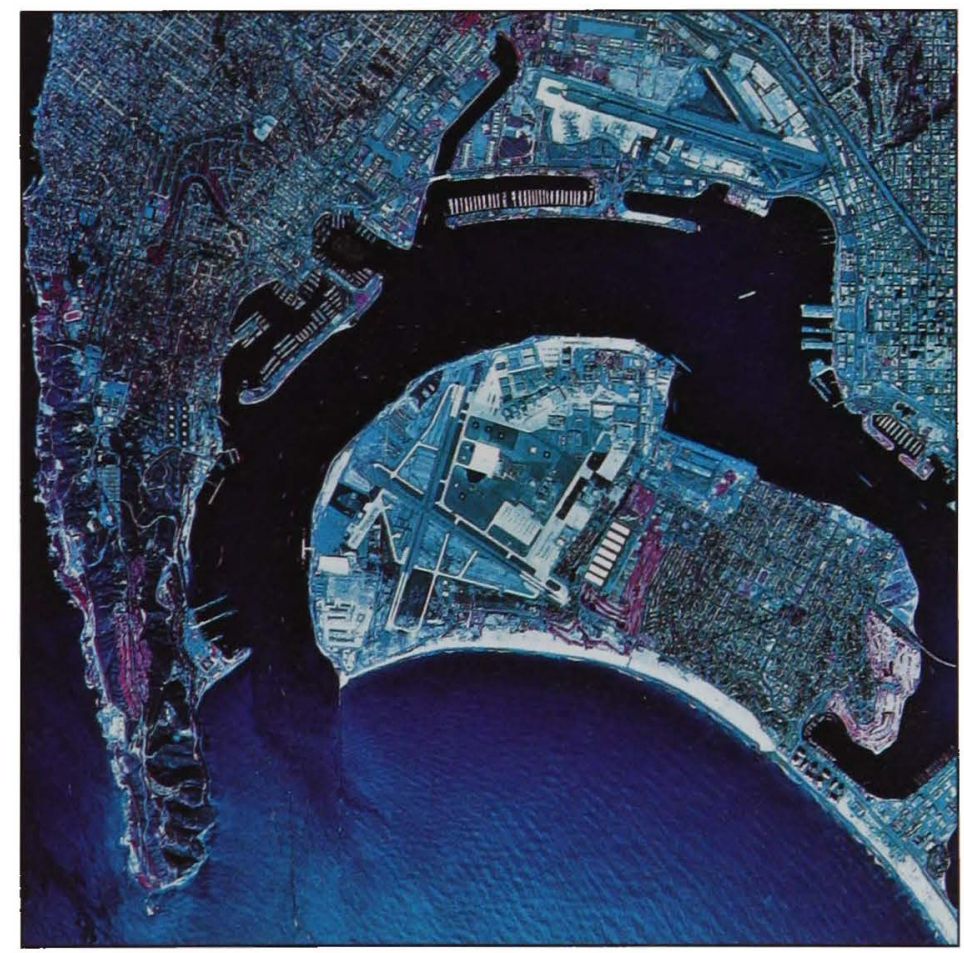

Figure 4: San Diego, Calif., National Aerial Photography Program color-infrared photograph, February 1985

Figure 1: (Front Cover), La Jolla, Calif., National Aerial Photography Program color-infrared photograph, September 1990

4 Figure 2: (Inside Front Cover), Cape Cod, Mass. Landsat 1 multispectral scanner satellite image, April 1974

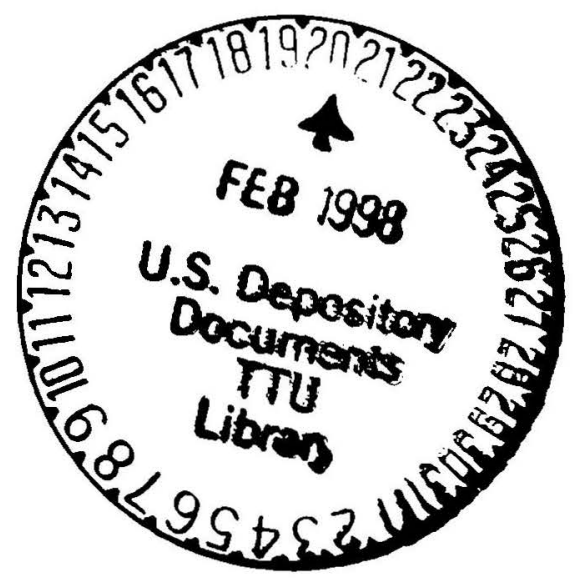


in

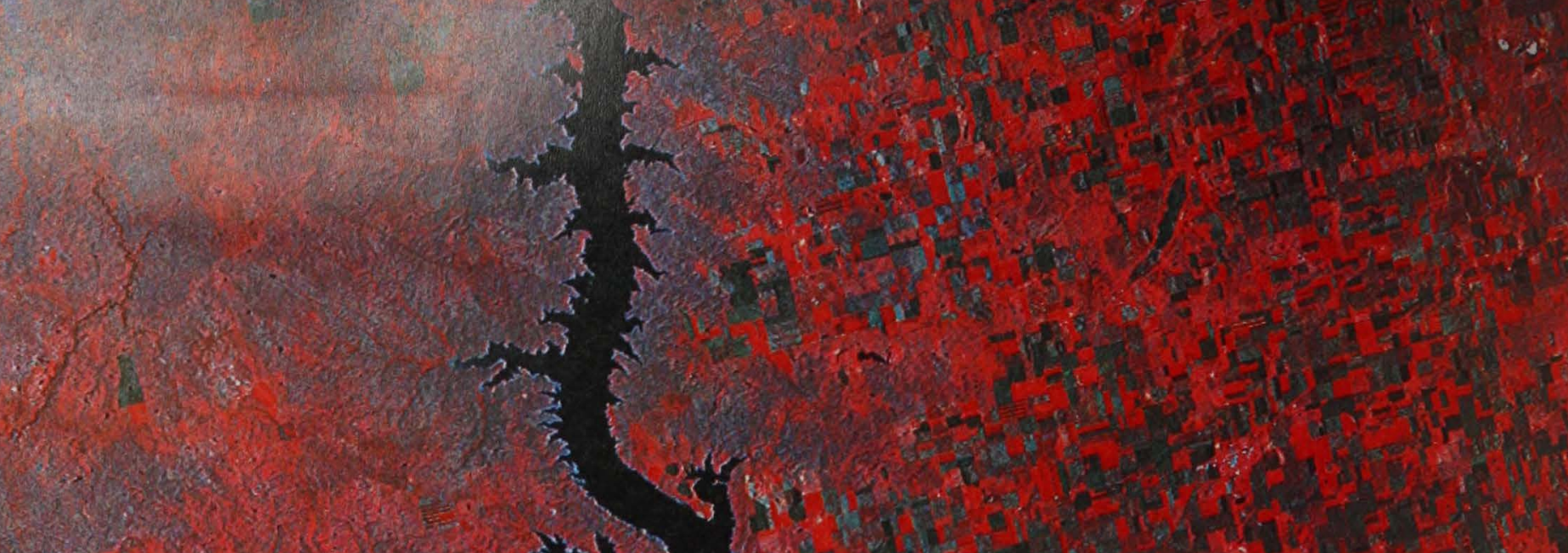
(1)

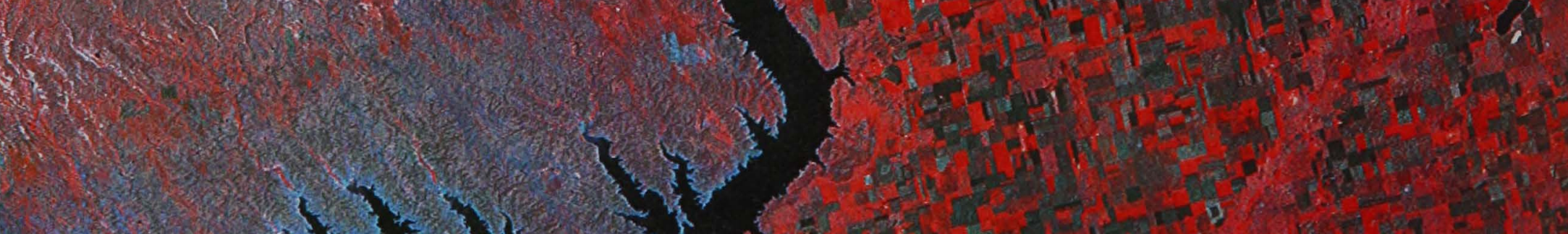
(1) 


\section{How Images Are Categorized}

Remotely sensed images are usually categorized according to the altitude of the aircraft or spacecraft and the characteristics of the sensors used to generate the images.

\section{Altitude}

Satellites, including manned spacecraft, usually collect images from hundreds of miles above the Earth's surface while aircraft operate at altitudes from a few thousand to more than 60,000 feet. The altitude from which an image is taken and the physical characteristics of the sensor, such as the lens focal length in the case of cameras, largely determine the area covered and the amount of detail shown. In general, the level of detail is greater in low-altitude photographs that cover relatively small areas, while satellite images cover much larger areas but show less detail.

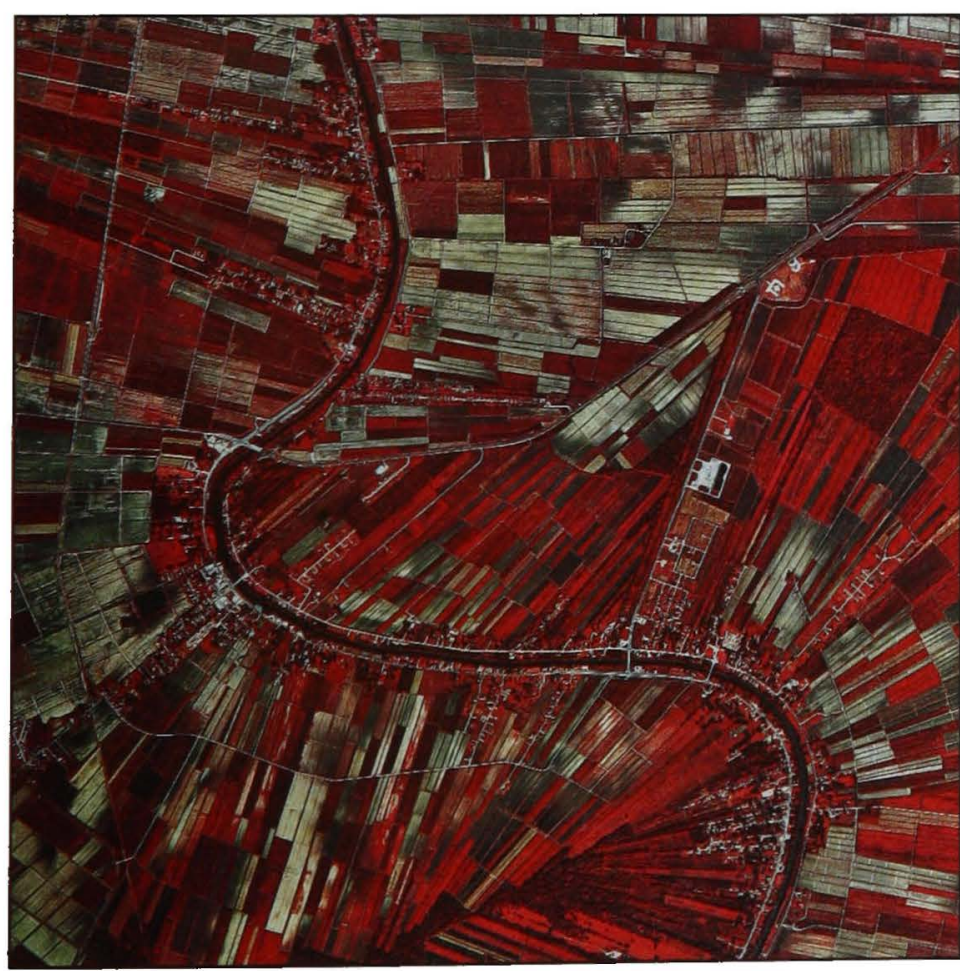

Figure 6: Bayou Lafourche, La., National Aerial Photography Program color-infrared photograph, October 1990

\section{Sensor and Media Characteristics}

Aerial photographs are produced by exposing film to solar energy reflected from the Earth. Photographic media have been used for aerial reconnaissance since the middle of the 1860's; color film became widely used in the 1950's. Color-infrared film, which records energy from portions of the electromagnetic spectrum invisible to the human eye, was developed to detect camouflaged military objects in the 1940's. In a colorinfrared (also known as a false-color) photograph, near-infrared light reflected from the scene appears as red, red appears as green, green as blue, and blue as black. Color-infrared film is useful for distinguishing between healthy and diseased vegetation, for delineating bodies of water, and for penetrating atmospheric haze.

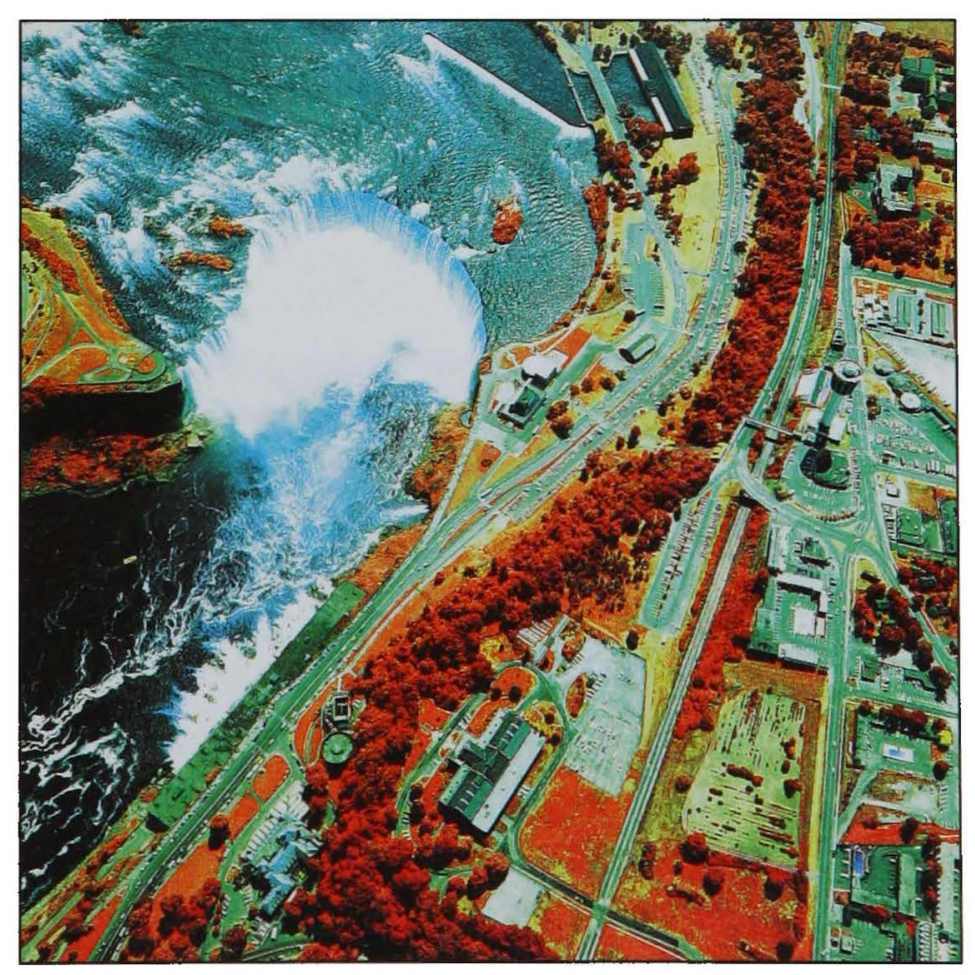

Figure 7: Horseshoe Falls (Niagara Falls), N.Y. and Canada, looking south, low oblique color-infrared aerial photograph, Environmental Protection Agency, August 1974 


\section{How Images Are Categorized}

Black-and-white and color-infrared films are used today in both high- and low-altitude aerial photography. Natural-color film is used more rarely because it is often affected by atmospheric haze.

Cameras of various types are used to take aerial photographs. Although cameras have also been carried on spacecraft such as the Space Shuttle, satellites more frequently use electronic scanners to record ground scenes in digital form. These sensors record reflected or emitted energy in the visible, near-infrared, and thermal-infrared portions of the spectrum. Satellite scanner data are commonly displayed as images

\section{Views of the same area from progressively higher altitudes and finer resolution}

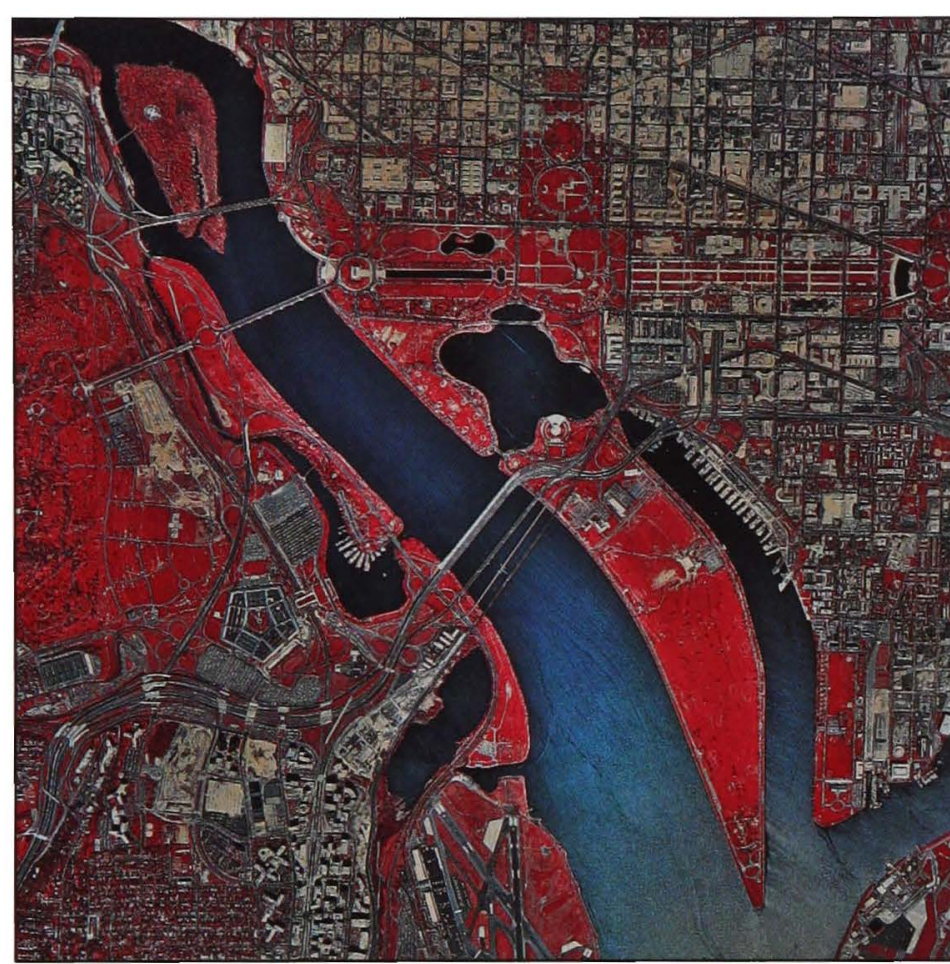

Figure 8: Medium-altitude National Aerial Photography Program color-infrared aerial photograph of Washington, D.C., taken from 20,000 feet, April 1988

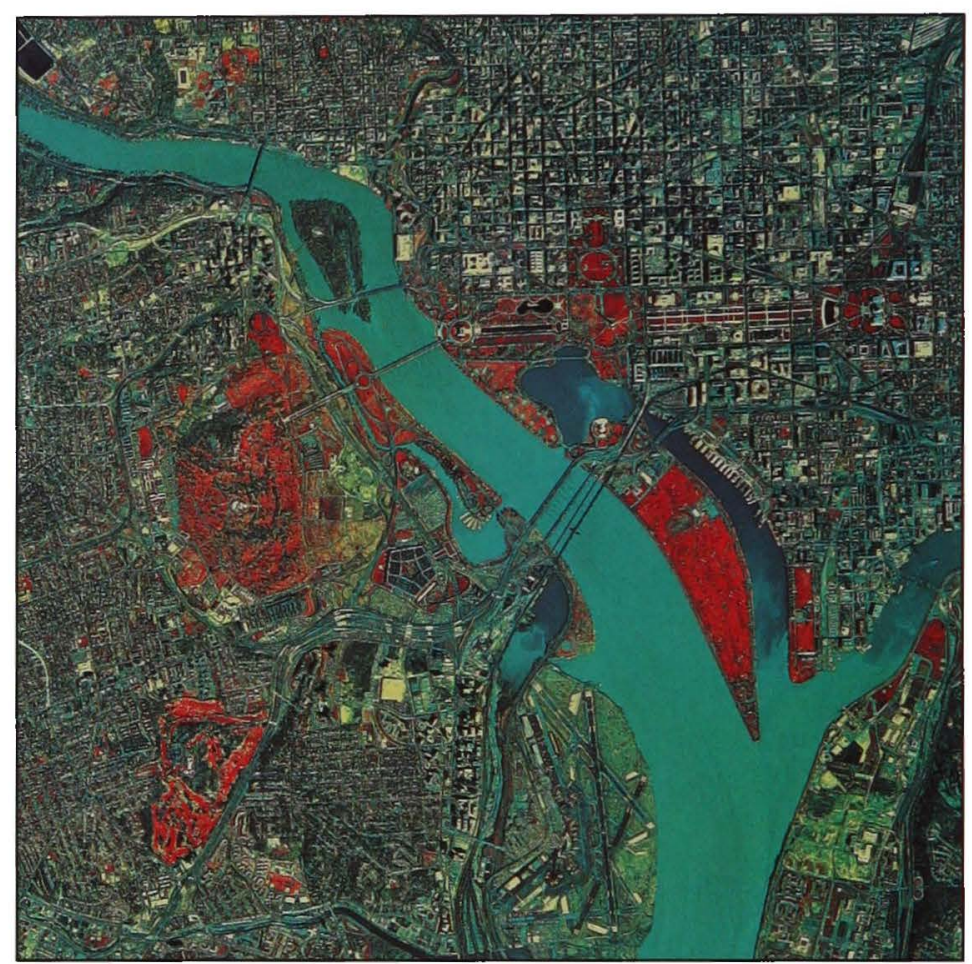

Figure 9: High-altitude National High Altitude Photography program color-infrared aerial photograph of Washington, D.C., taken at 40,000 feet, March 1982

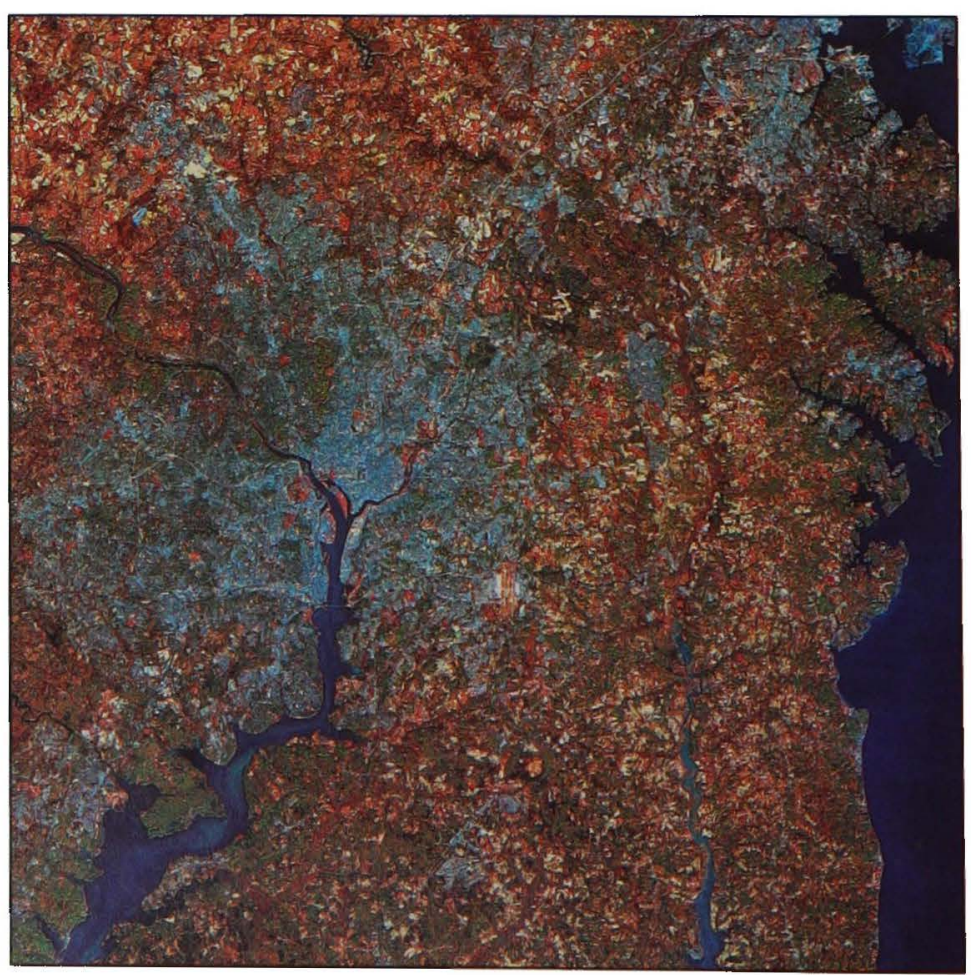

Figure 10: Washington, D.C., area Landsat 5 thematic mapper satellite image taken from $705 \mathrm{~km}$, January 1984 
whose colors resemble those of color-infrared aerial photographs, but the colors of a given image can be manipulated by computer to enhance landscape features. Although certain satellite images are distributed as photographic film or prints, they are more often distributed as digital products.
Side-looking airborne radar (SLAR) instruments on aircraft or satellites generate their own energy, which is recorded on being reflected back to them from the ground. This eliminates problems associated with cloud cover and haze. The oblique angle of the "side-looking" instrument yields images that are especially useful in analyzing landforms.

\section{Comparison of four types of image media of the same area}

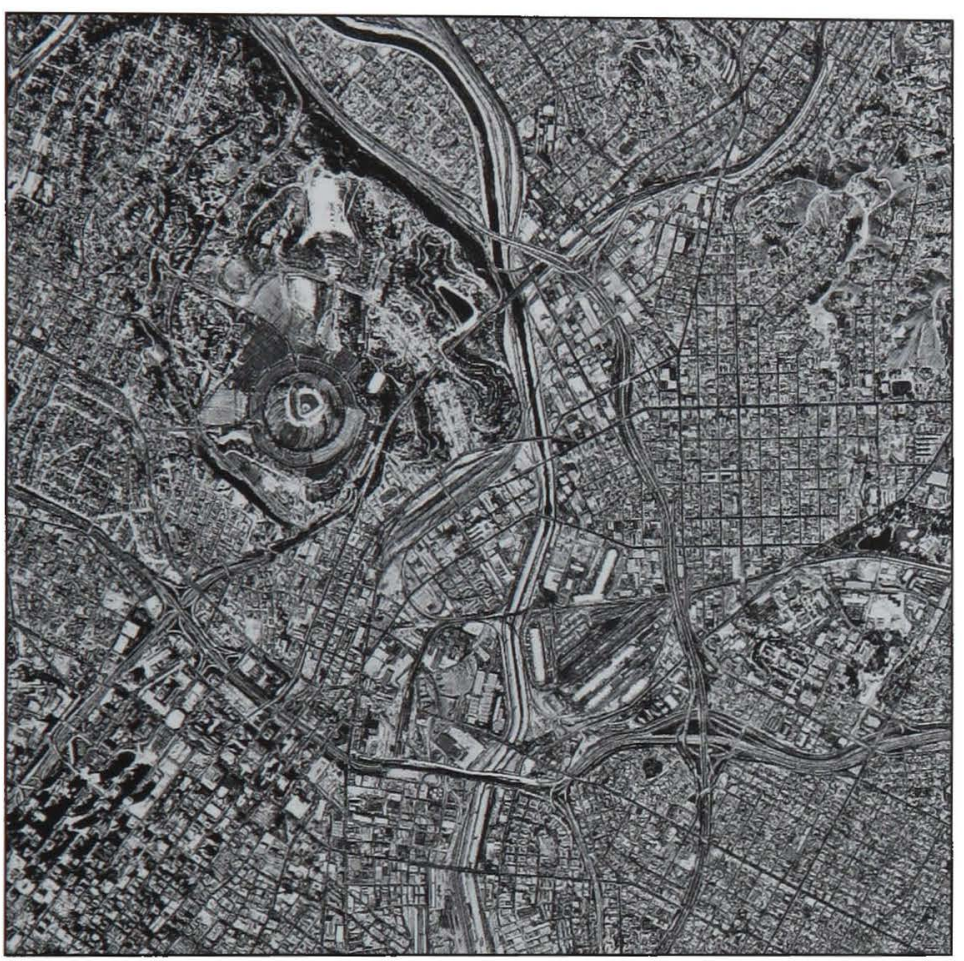

Figure 11: Los Angeles, Calif., National Aerial Photography Program black-and-white aerial photograph, August 1989

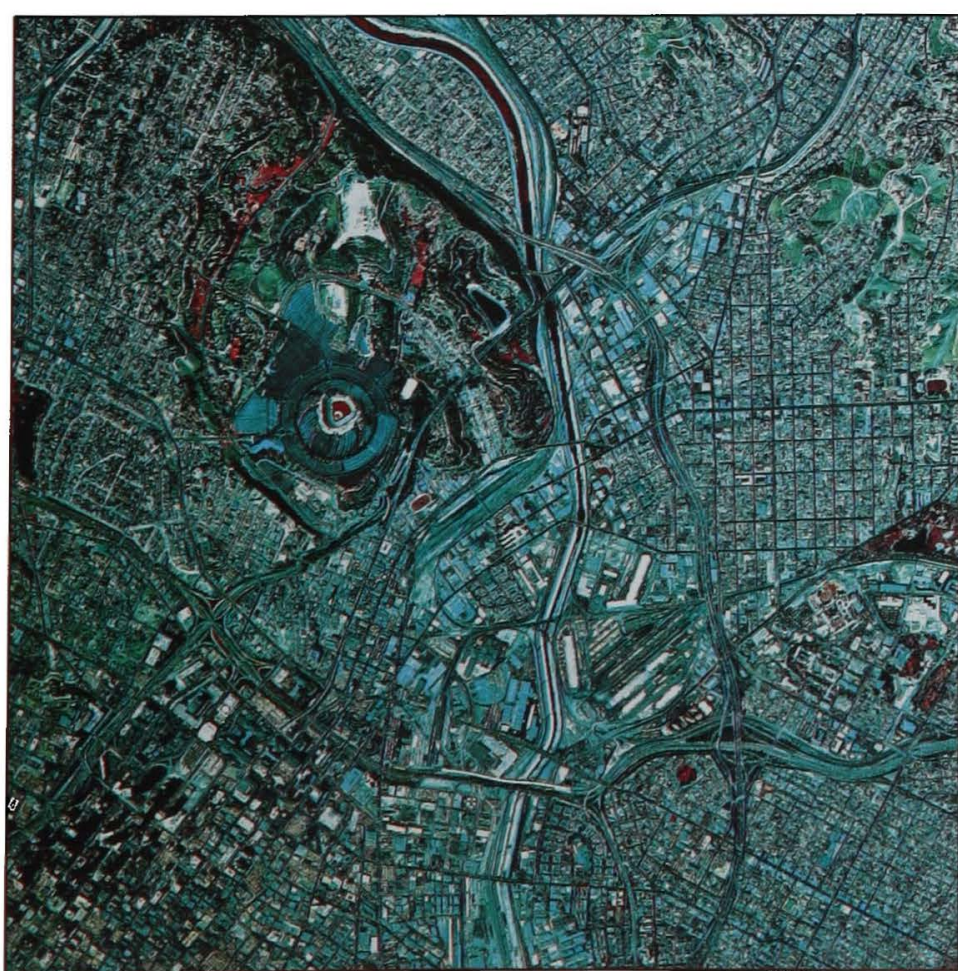

Figure 13: Los Angeles, Calif., National Aerial Photography Program color-infrared aerial photograph, August 1989

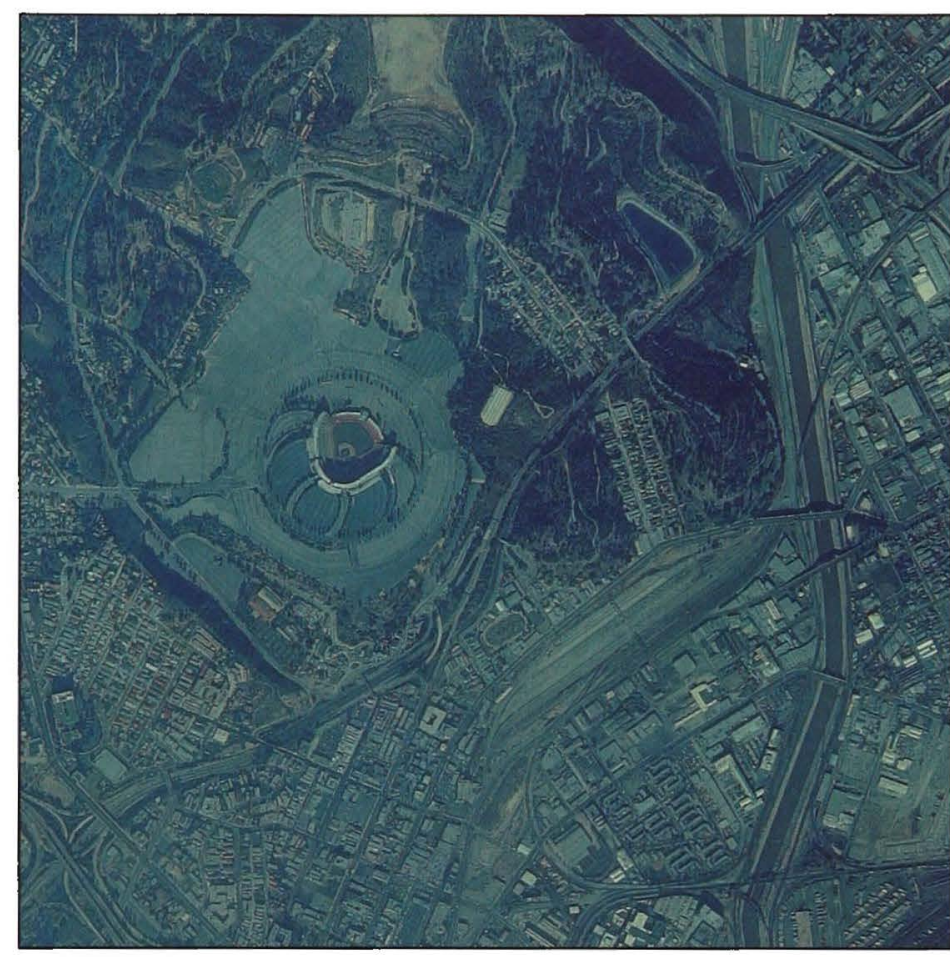

Figure 12: Los Angeles, Calif., NASA natural-color aerial photograph

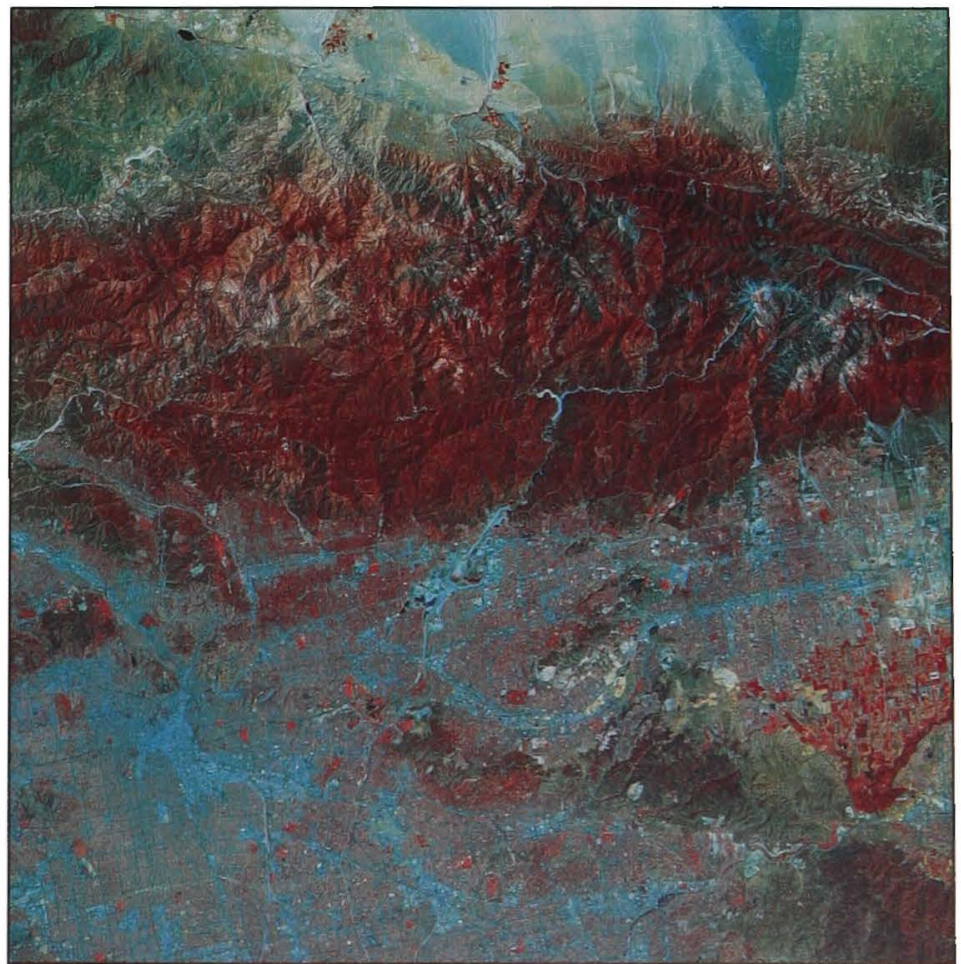

Figure 14: Los Angeles, Calif., Landsat 5 thematic mapper satellite image, November 1987 


\section{Aerial Photographs}

Although the USGS has used aerial photographs for many decades, the availability of photographs from the earliest years is limited. Most recent photographs are from programs covering all 50 States and were taken with predominantly blackand-white film, with some instances of colorinfrared use.

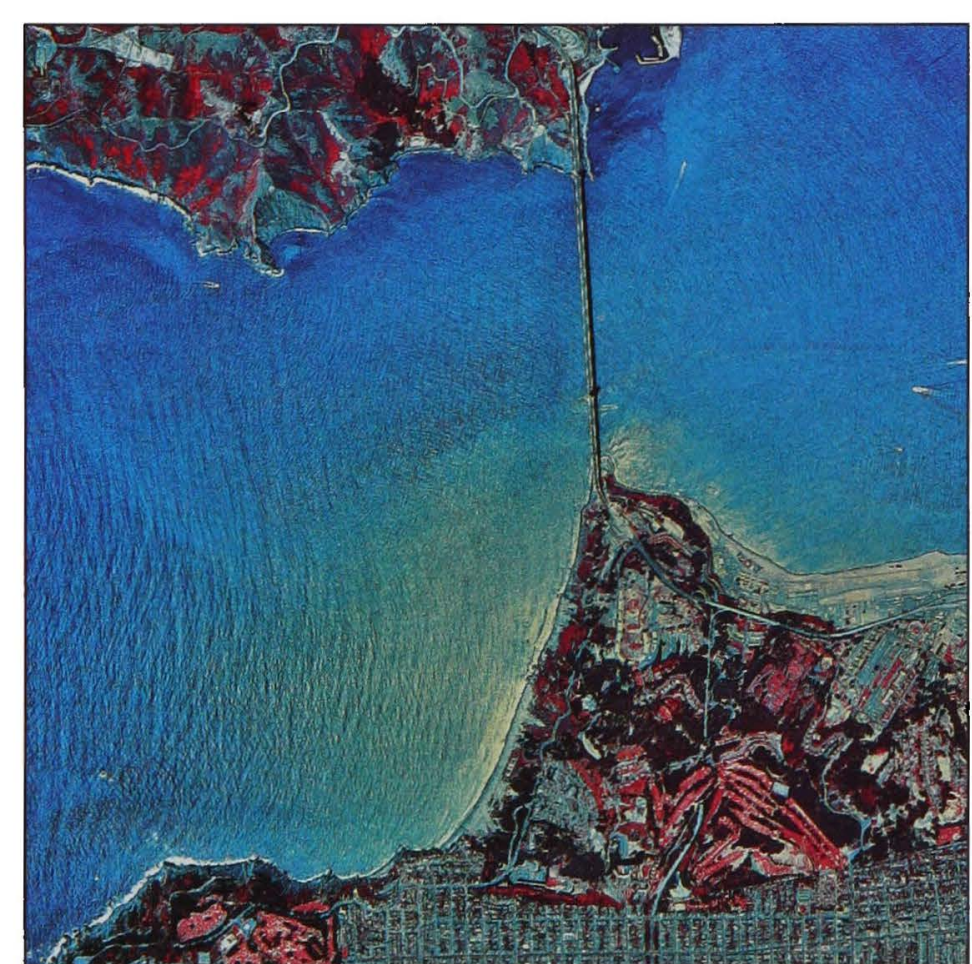

Figure 15: Golden Gate Bridge, San Francisco, Calif., National Aerial Photography Program color-infrared aerial photograph, June 1987

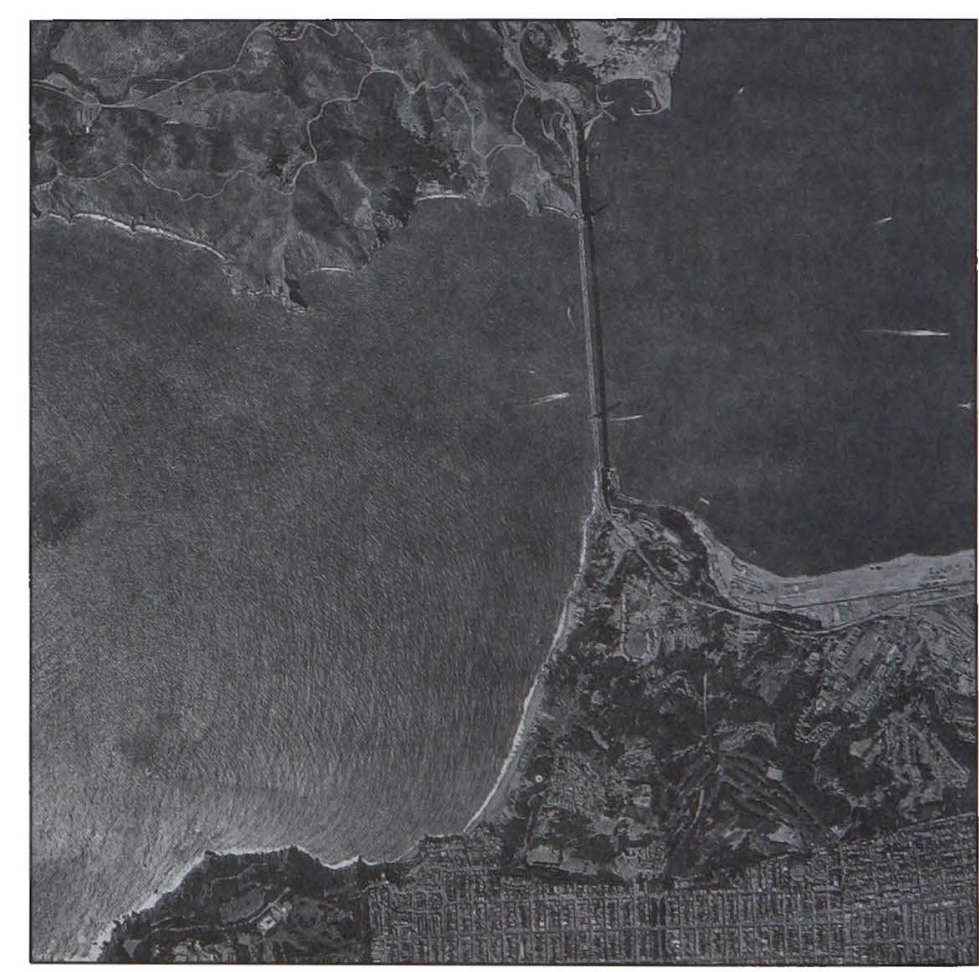

Figure 16: Golden Gate Bridge, San Francisco, Calif., National Aerial Photography Program black-and-white aerial photograph, August 1993 


\section{National Aerial Photography Program}

The National Aerial Photography Program (NAPP) was established in 1987 to coordinate aerial photography for the United States among Federal and State agencies. NAPP photographs are used for such purposes as mapping, resource planning, engineering, land use planning, and agricultural monitoring. Private citizens also purchase them for hunting, hiking, and other recreational purposes, as well as for inherent qualities such as an unusual perspective on familiar landscapes. Taken from aircraft flying nominally at 20,000 feet above the terrain, each NAPP photograph covers about 32 square miles.

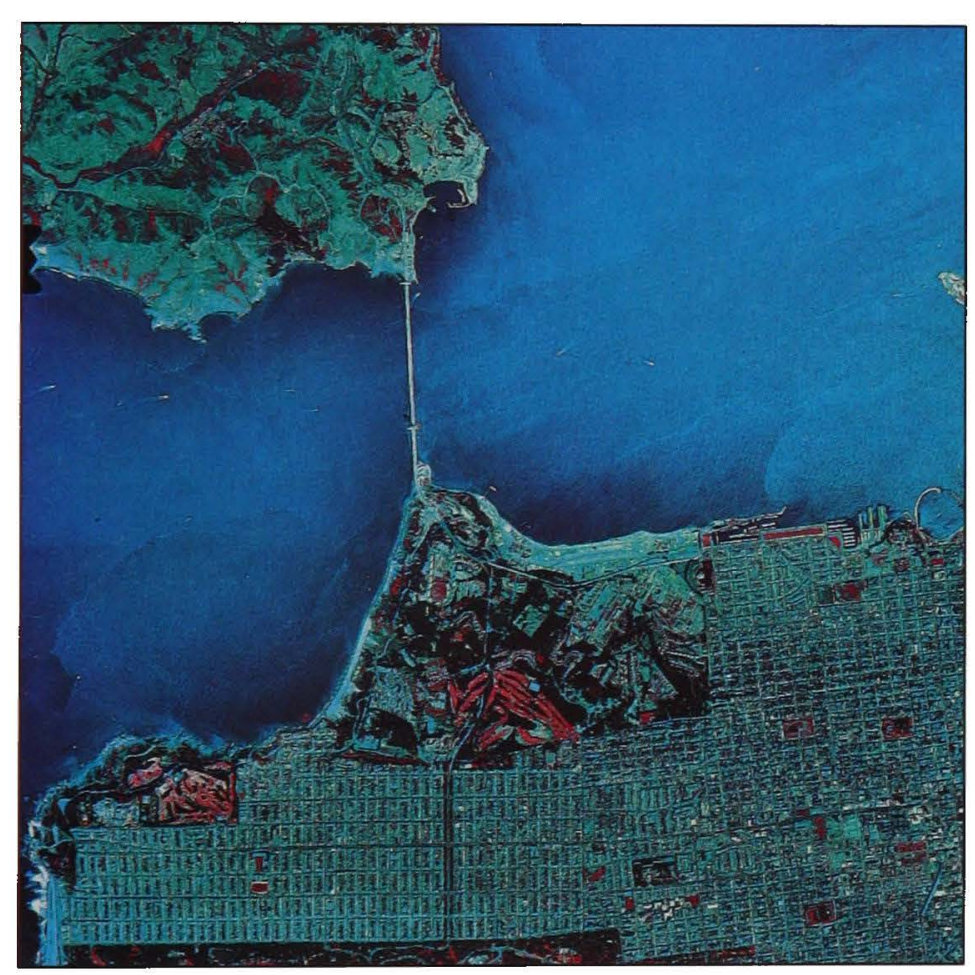

Figure 17: Golden Gate Bridge, San Francisco, Calif., National High Altitude Photography program color-infrared aerial photograph, August 1982

\section{National High Altitude Photography Program}

The National High Altitude Photography (NHAP) program was a Federal project that preceded NAPP, running from 1978 to 1988. NHAP photographs were taken simultaneously with two cameras, one containing black-and-white film, the other color infrared. The NHAP aircraft flew at 40,000 feet. These photographs cover more area, but show less detail, than NAPP photographs. An NHAP black-and-white photograph covers about 129 square miles, and because of the longer focal length in the second camera, an NHAP color-infrared photograph covers about 68 square miles.

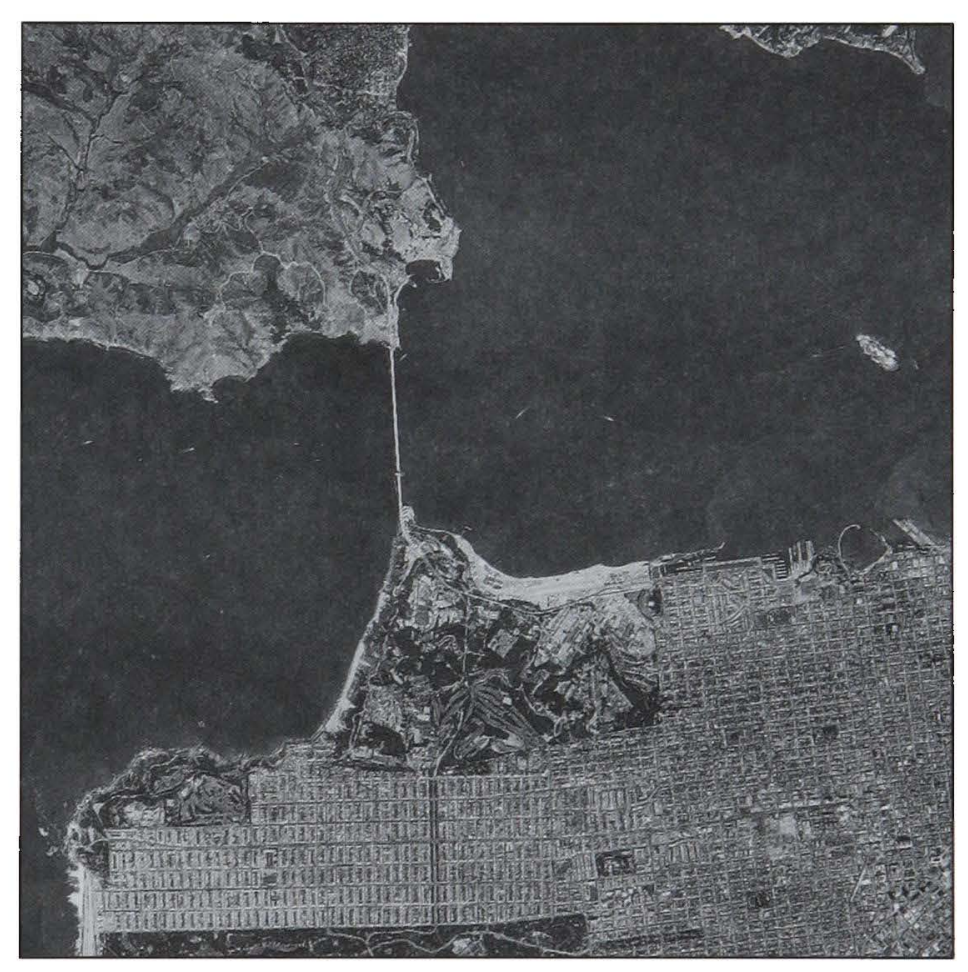

Figure 18: Golden Gate Bridge, San Francisco, Calif., National High Altitude Photography program black-and-white aerial photograph, August 1982 


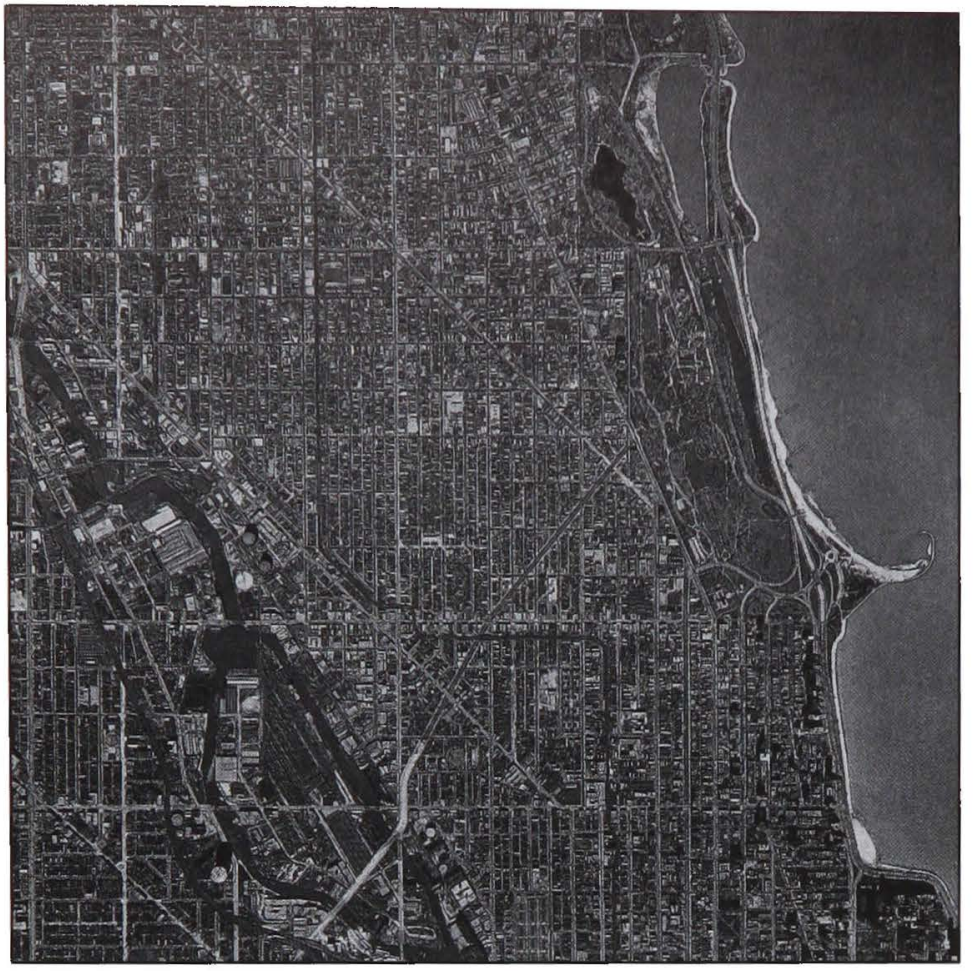

Figure 19: Chicago, III., and Lake Michigan shoreline, USGS project, black-and-white aerial photograph, March 1952

\section{Aerial photographs from Federal mapping programs}

The USGS archives photographs it has used for making maps, as well as mapping photos from some other Federal agencies. Some of these black-and-white photographs date to the 1950's. Most show more detail than NAPP and NHAP photographs.

\section{Aerial photographs from NASA}

NASA uses aerial photographs for research and to test remote sensing techniques and instruments. These photographs, available in various formats, were taken from altitudes of a few thousand feet up to more than 60,000 feet. NASA aerial photographs may be available in black and white, natural color, or color infrared.

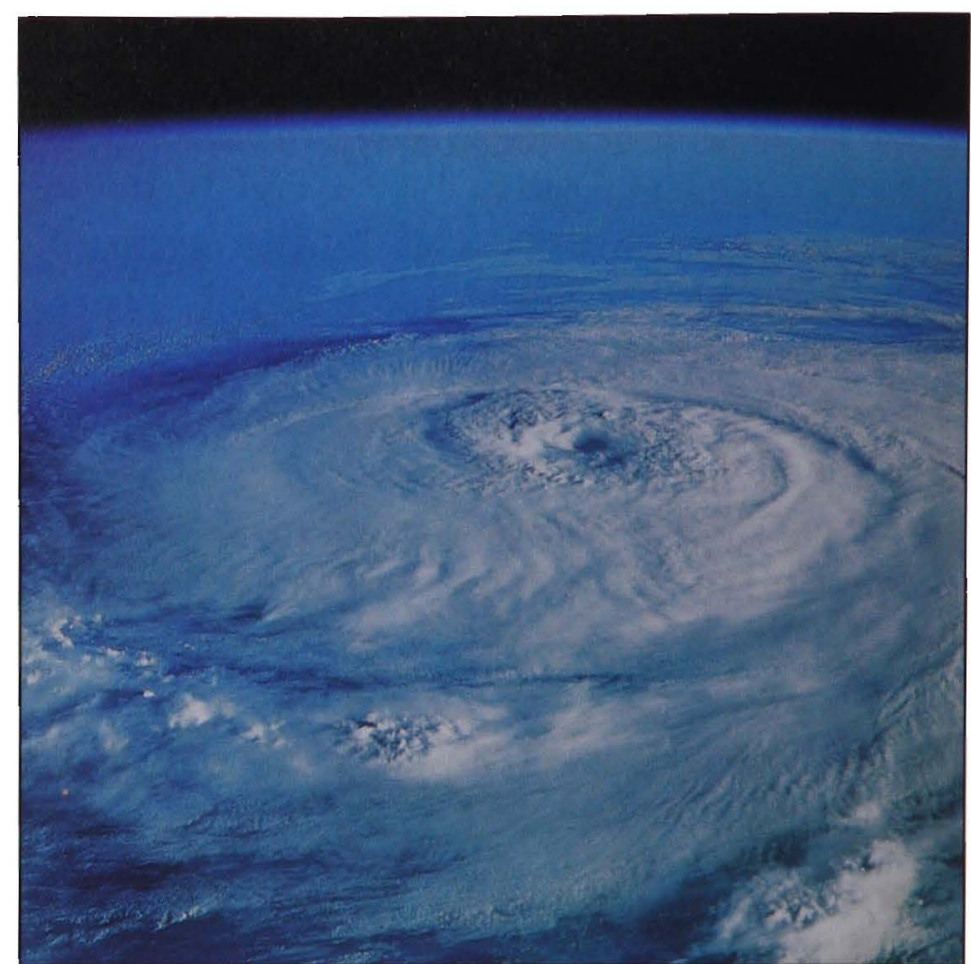

Figure 20: Hurricane Elena, Space Shuttle photograph over the Gulf of Mexico, September 1985

\section{Aerial photographs from other Government agencies}

Along with its archive of USGS photos, the Earth Resources Observation Systems (EROS) Data Center of the USGS stores negatives of aerial photographs from other Federal agencies, including the Bureau of Land Management, the Bureau of Reclamation, the Bureau of Indian Affairs, NASA, and the Armed Forces.

\section{Orthophotos and digital orthophotos}

Orthophotos are aerial photographs or digital versions of these photographs that have been "orthorectified" using ground elevation data to correct displacements caused by differences in terrain relief and camera tilt. The process gives an orthophoto the accuracy of a map. Because aerial photographs show the texture of the ground in much greater detail than do maps, orthophotos are useful for updating maps and for studying surface features not necessarily visible in maps. The USGS produces digital orthophotos for map revision and for computer analysis using geographic information systems. Coverage of the entire country in these digital products is in progress. 


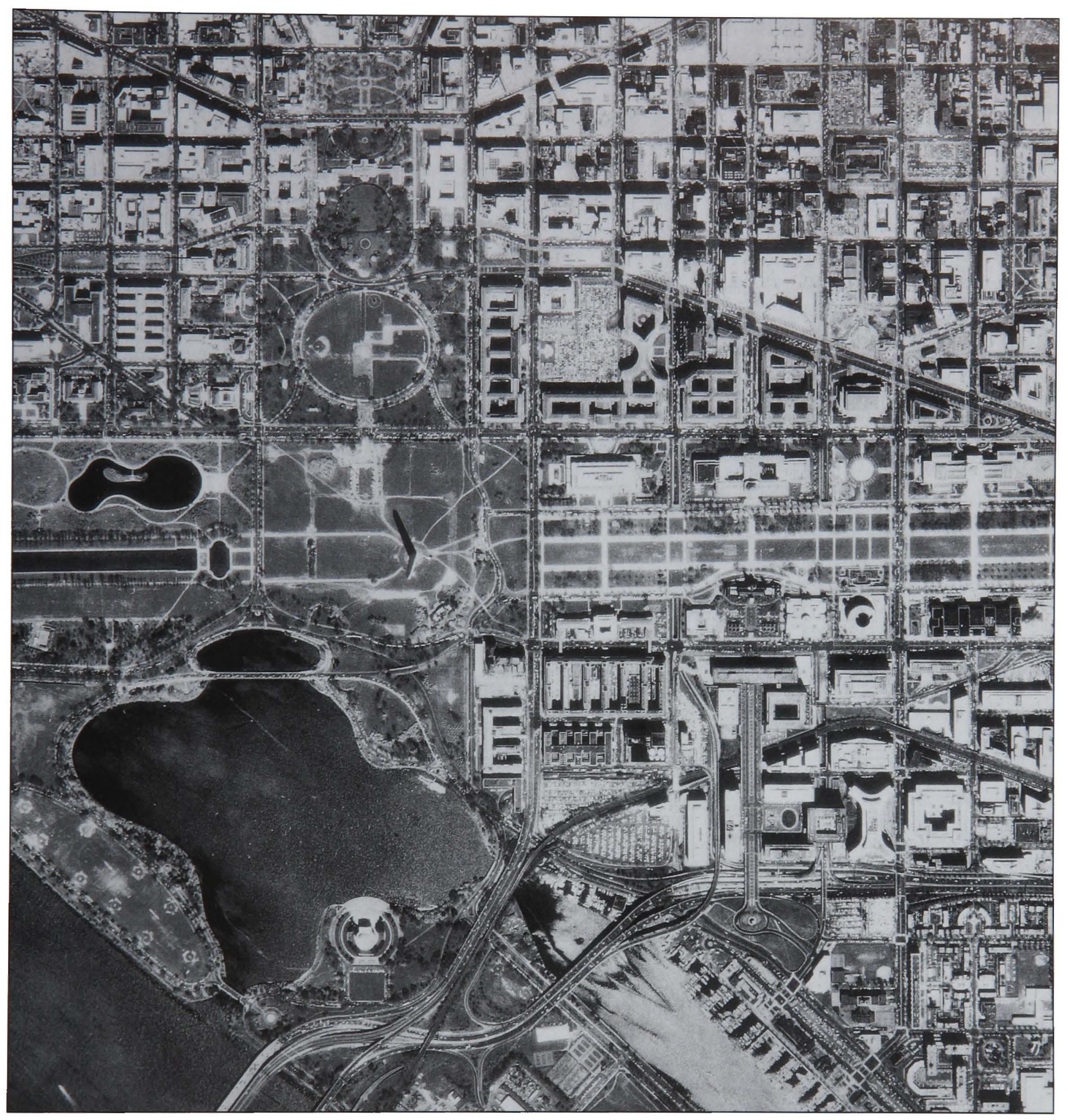

Figure 21: Washington, D.C., section of a 1-m

resolution, quarter-quadrangle digital orthophoto

date of aerial photograph, April 1988 


\section{Side-looking airborne radar}

Because SLAR systems provide their own energy to illuminate the ground, the images they produce can be collected regardless of weather or time of day. So the images are valuable for mapping parts of the world that are perpetually cloud covered, such as the Amazon Basin. SLAR systems transmit microwave energy to the ground from aircraft. The signal strikes the ground and is reflected and scattered. The portion of the signal that returns to the sensor is recorded as digital values that can be represented on photographic film. The side-looking geometry of the system produces shadows of varying lengths depending on the angle of illumination and the surface relief. Although these shadows enhance subtle terrain features, such as faults and folds, they also obscure detail in the shadow areas. SLAR images are useful to scientists studying geologic structures. SLAR images most often consist of image strips and 1:250,000-scale

mosaics prepared from these strips. Some SLAR data are available on CD-ROM.

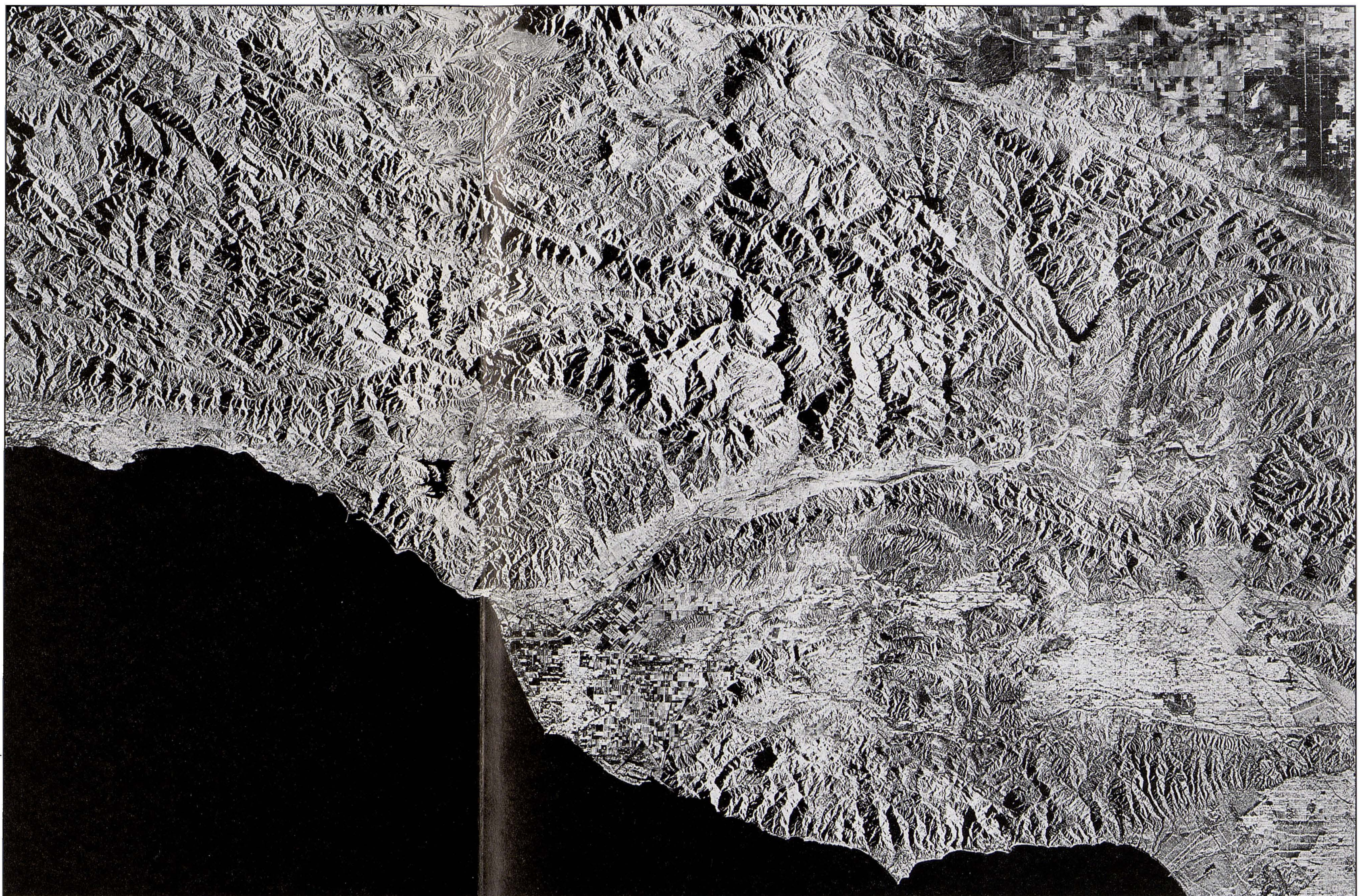

Figure 22: Los Angeles, Calif., side-looking airborn radar (SLAR) mosaic compiled from imagery 


\section{Aerial Photographs}

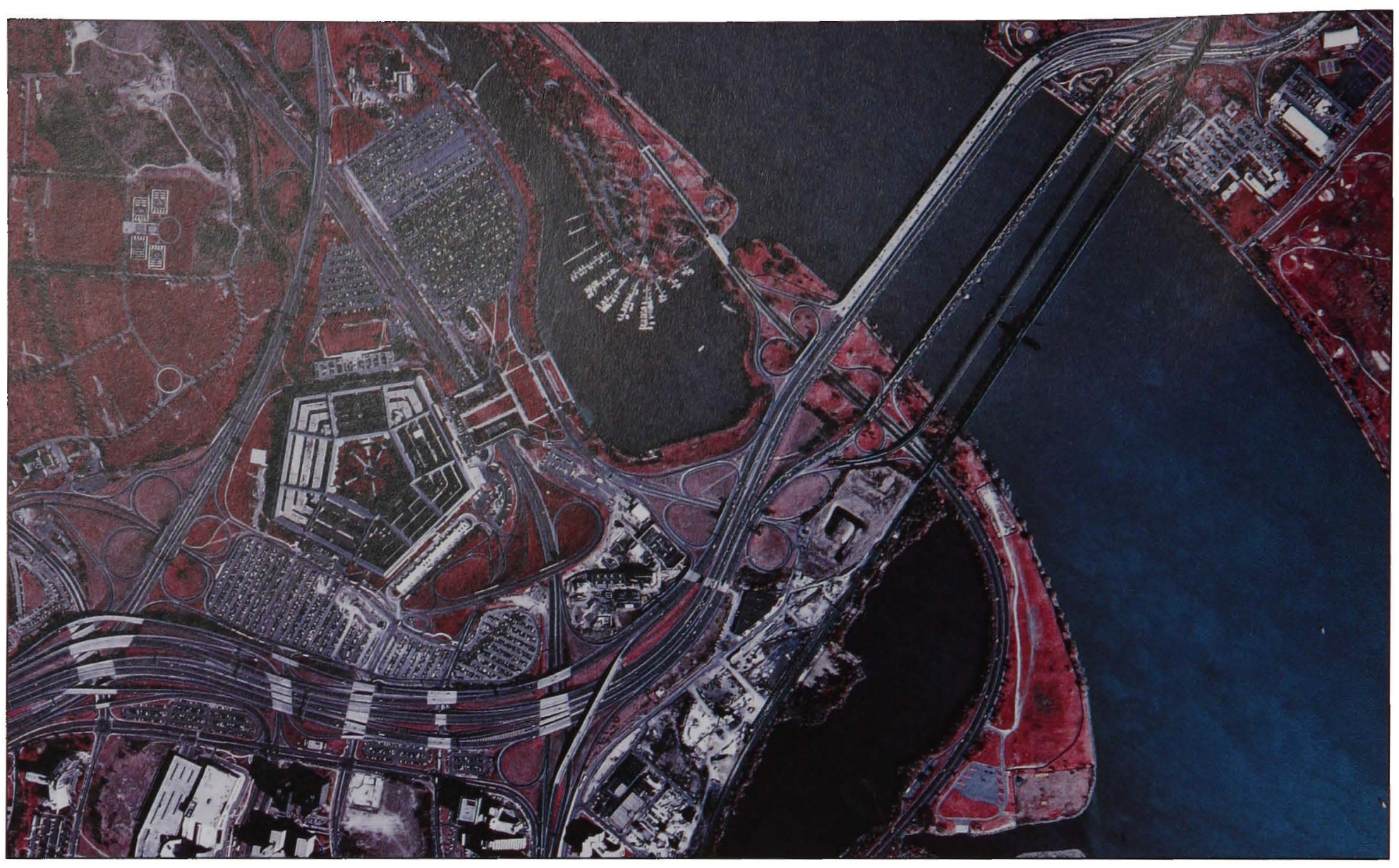

Figure 23: The Pentagon and vicinity, Washington, D.C., portion of a National Aerial Photography Program 9-inch aerial photograph, 1:40,000-scale, March 1994

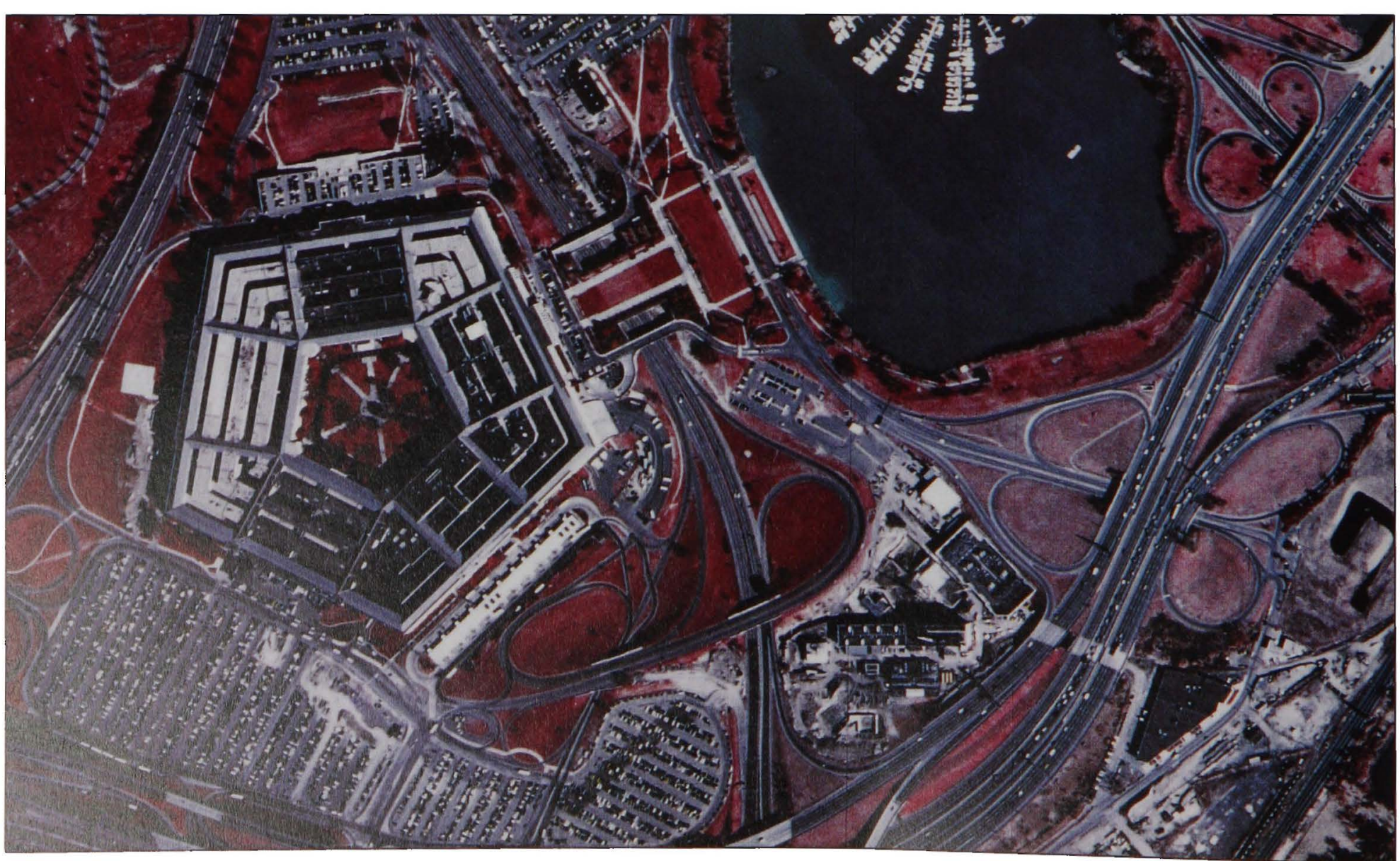

Figure 24: The Pentagon and vicinity, Washington, D.C., portion of a National Aerial Photography Program 18-inch

$2 \mathrm{X}$ enlargement, 1:20,000-scale, March 1994 


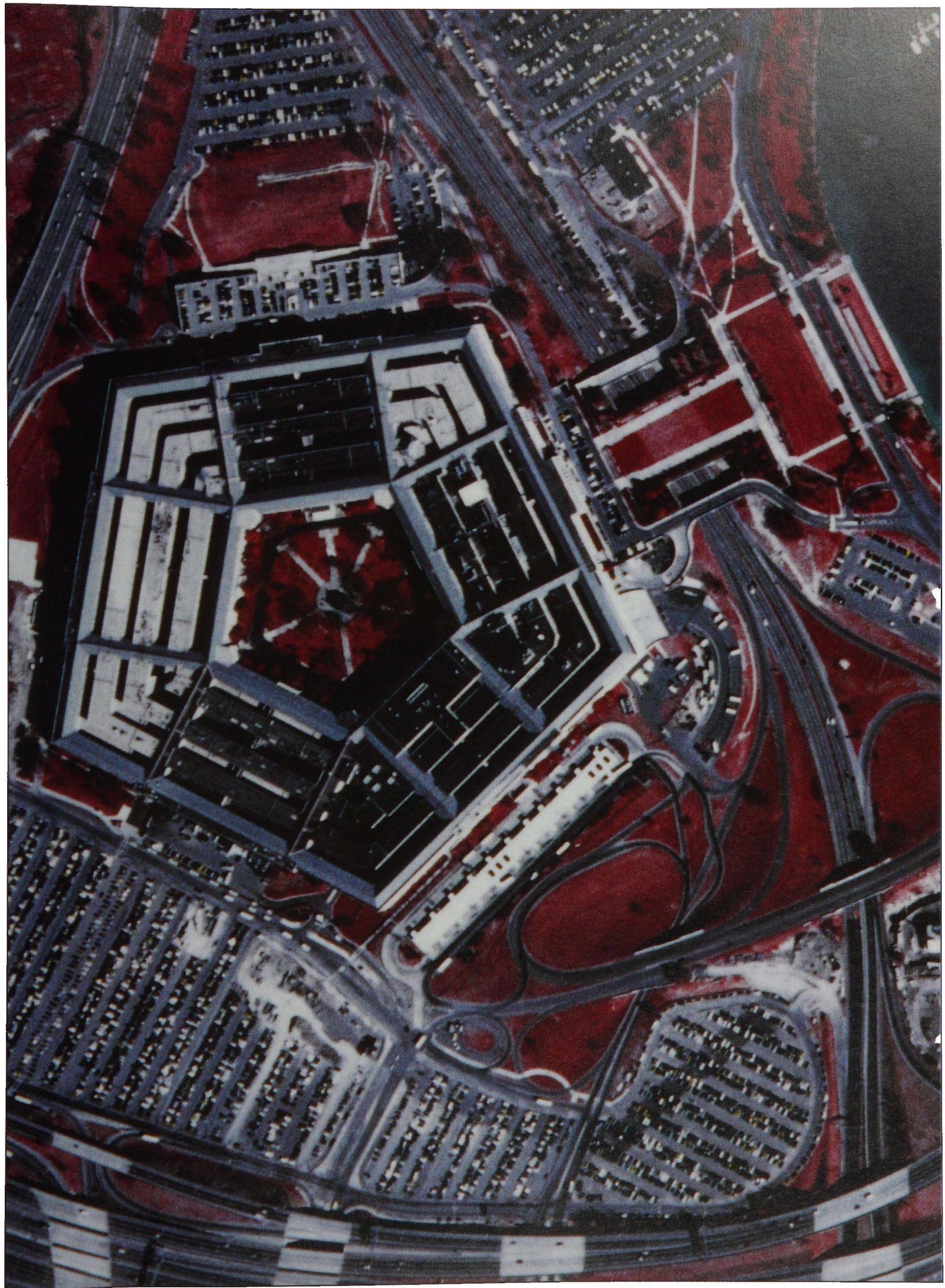

Figure 25: The Pentagon and vicinity, Washington, D.C.,

portion of a National Aerial Photography Program 36-inch

4 X enlargement, 1:10,000-scale, March 1994 


\section{Satellite Images}

The EROS Data Center processes and stores satellite data from several satellites. The major types are:

\section{Manned spacecraft photographs}

Photographs were taken over limited areas of the Earth on NASA's Gemini (1965-66) and Apollo (1968-69) missions. Three Skylab missions in 1973 and 1974 resulted in more than 35,000 photographs.

Astronauts aboard the Space Shuttle, which began flying in 1981, have taken many photographs of the Earth with hand-held cameras. These photographs document sites of scientific interest around the world and depict temporary phenomena such as hurricanes and erupting volcanoes. Most are in natural color.

\section{Landsat}

In 1972, the United States launched its first Earth Resources Technology Satellite, ERTS-1, later renamed Landsat 1, for experimental global coverage of the Earth's land masses. Landsats 2 through 5 were launched in 1975, 1978, 1982, and 1984.

Data from these satellites are collected by sensors that measure a range of wavelengths of electromagnetic energy reflected or emitted from the Earth. The data are transmitted to Earth, where they are processed by computers and stored on magnetic tape.
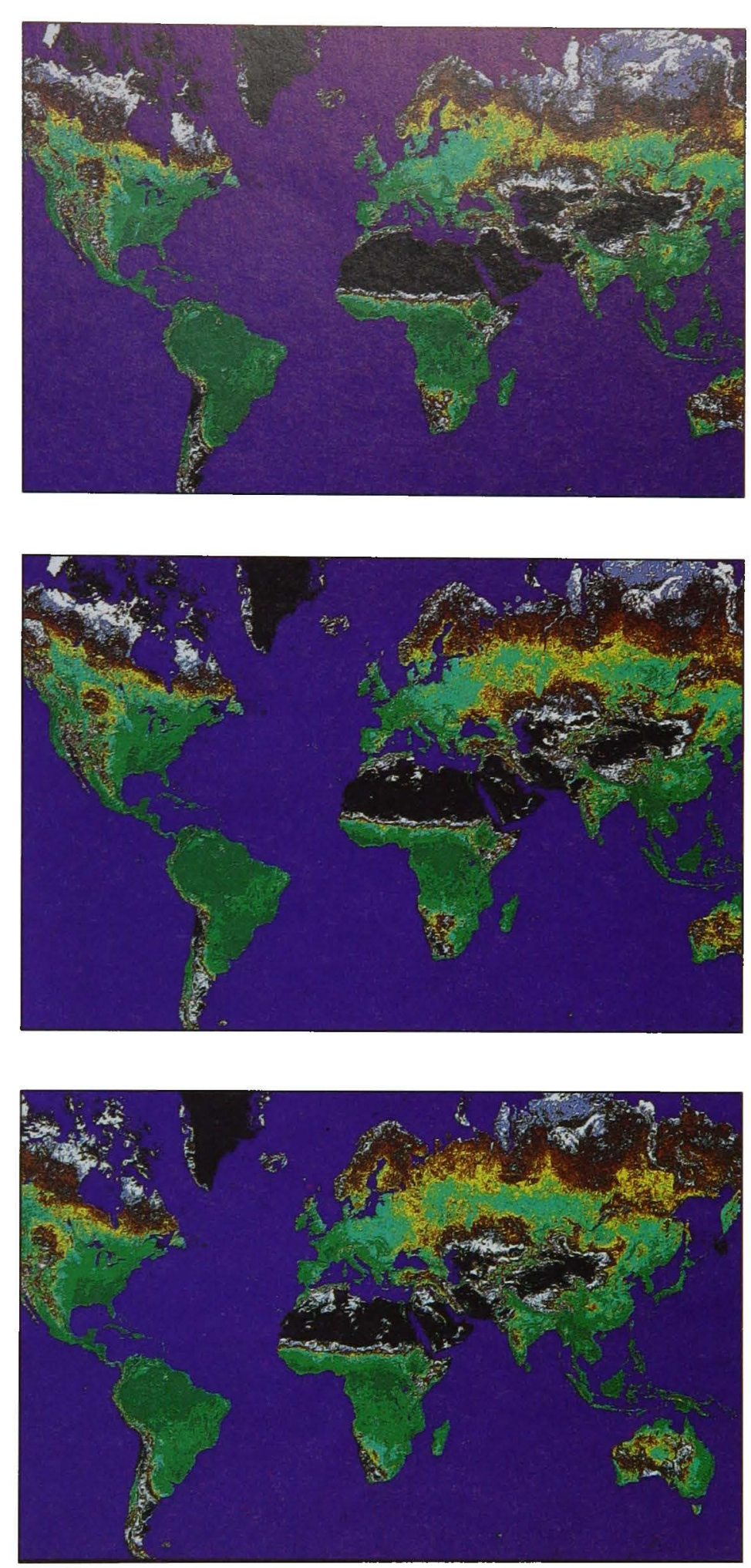

Figure 27: Global summation of vegetation "greenness" index for calendar years 1986-1988 (black = low greenness, dark green = high greenness), from AVHRR data, source - NOAA) 


\section{Satellite Images}

Landsats 1-5 carried versions of a sensor called the multispectral scanner (MSS), which collected data simultaneously from four broad bands of the electromagnetic spectrum, from visible green through near-infrared wavelengths. The MSS images in this booklet have a resolution of about 80 meters (260 feet).

The thematic mapper (TM) sensor carried on Landsats 4 and 5, in addition to the MSS, has a resolution of about 30 meters ( $98 \mathrm{feet}$ ). The TM sensor also records a greater number of bands
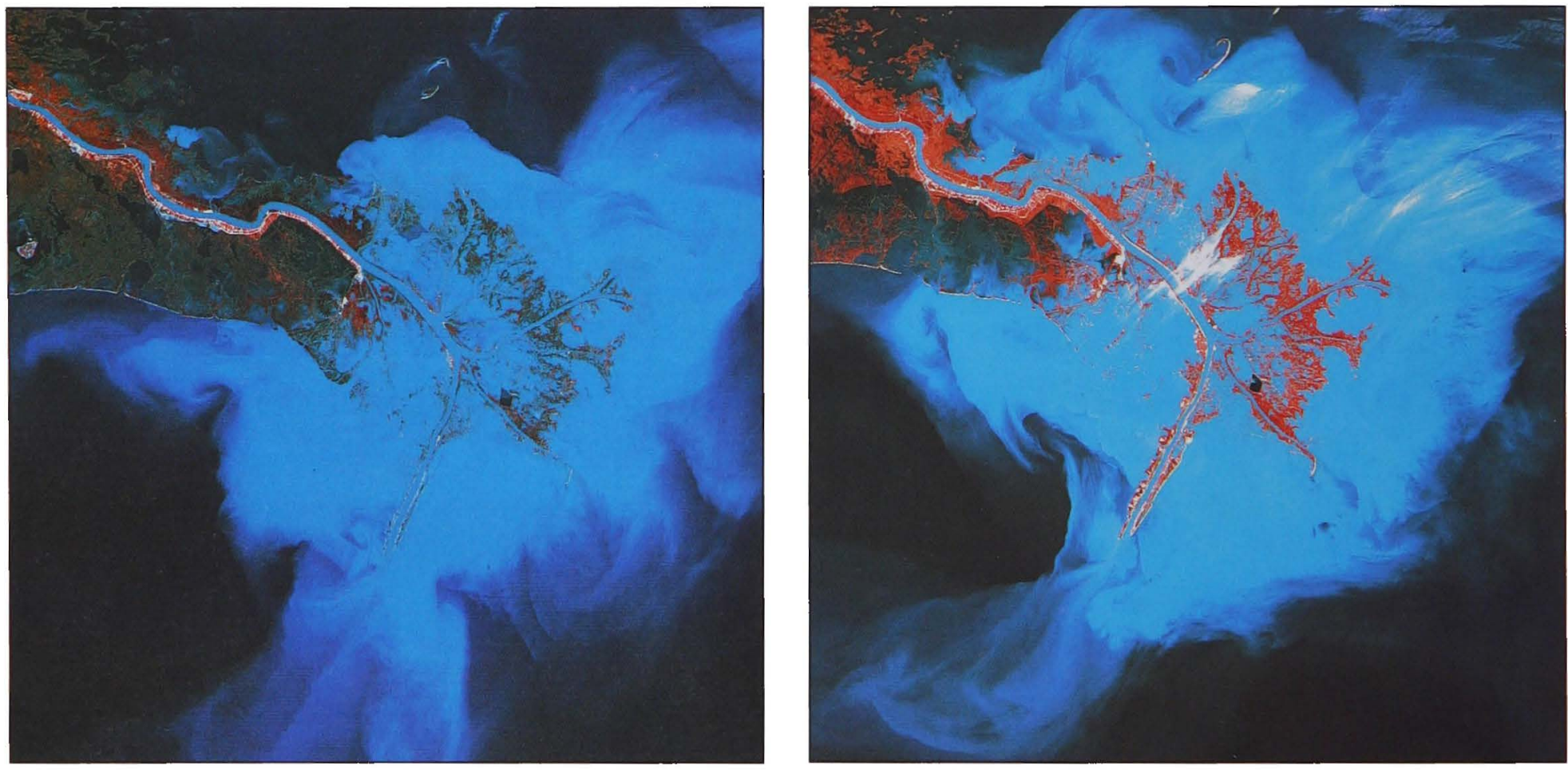
information. Landsat images can be processed to emphasize different features of the land.

Landsats 4 and 5 pass from north to south over the Equator at an altitude of 705 kilometers ( 438 miles) each day at about 10 a.m., and their orbits repeat coverage of the Earth, allowing the detection of change. Cloud cover and the need to transmit data directly to ground stations affect the than the MSS, yielding more detailed spectral amount of acceptable continuous repeat coverage.

Figure 28: Comparison of Landsat multispectral scanner satellite scenes of the Mississippi River Delta, January 16, 1973, and March 3, 1989 


\section{Spectral Sensitivity of Remote Sensing Systems}

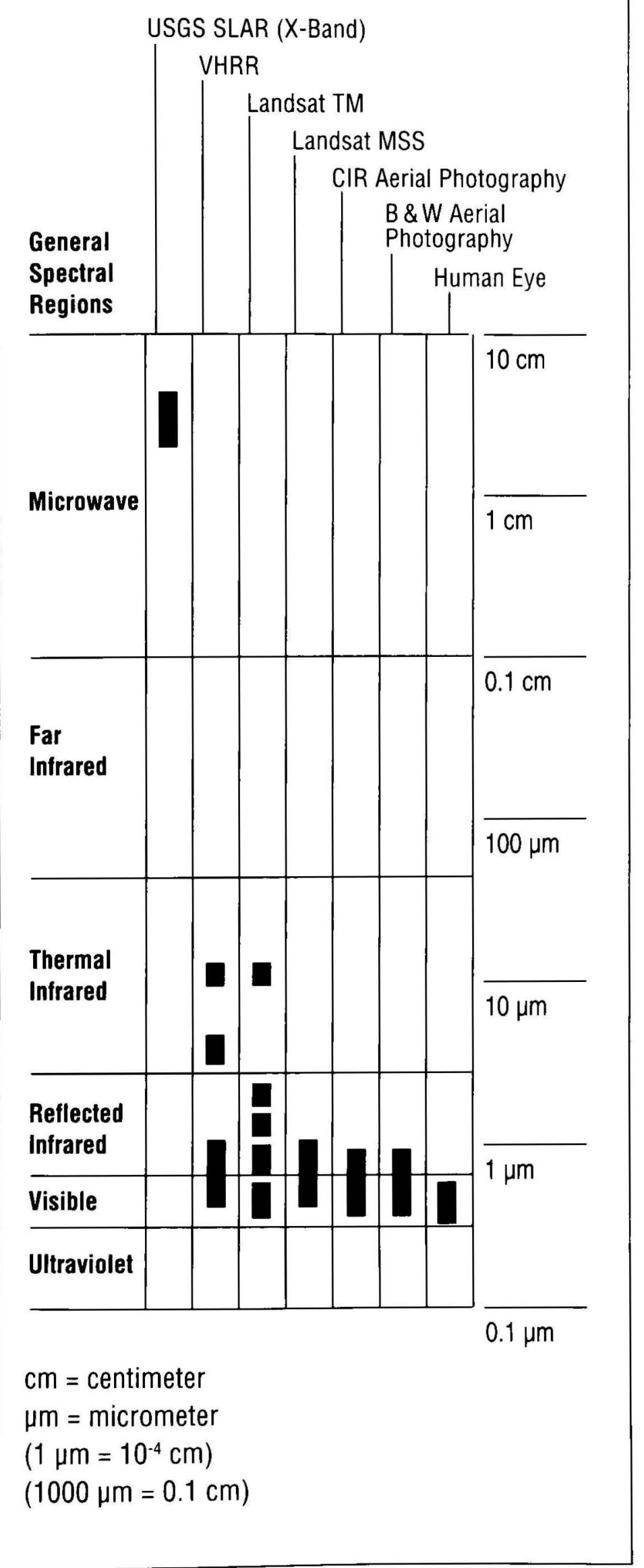

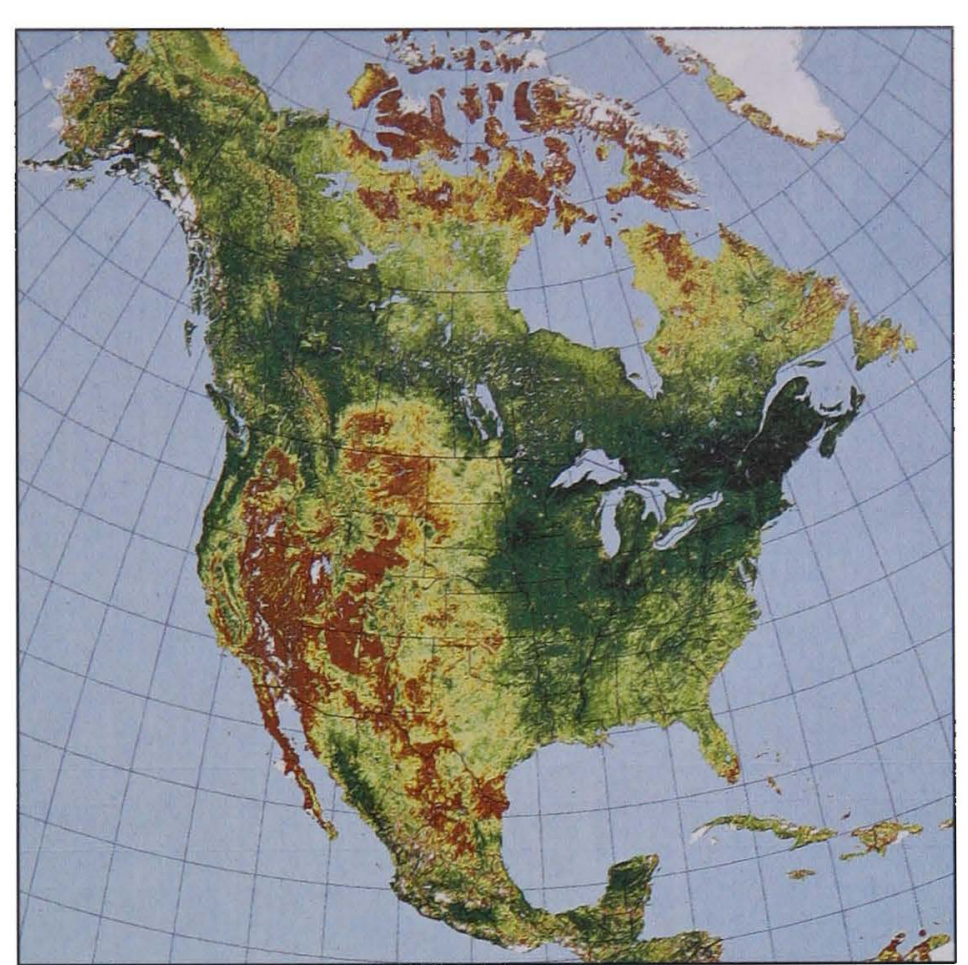

Figure 29: "Greenness" map derived from AVHRR satellite data, August 11-20, 1990

\section{Advanced very high resolution radiometer}

The advanced very high resolution radiometer (AVHRR) is one of several sensors aboard meteorological satellites operated by the National Oceanic and Atmospheric Administration. AVHRR data are collected in the visible, near-infrared, and thermal-infrared portions of the electromagnetic spectrum at a resolution of $1.1 \mathrm{~km}$ (about 0.68 mile). Two satellites each make 14 passes over the Earth in a 24-hour period, one locally in the morning and one in the afternoon. Thus, data are collected more frequently than Landsat data, but with much coarser resolution and for much larger areas.

The EROS Data Center has been processing $1 \mathrm{~km}$ resolution data from the AVHRR system since 1987 and using them for such applications as drought monitoring, fire fuel assessment, and land surface characterization. The use of these data for land management complements the traditional use of 4- and 16-km resolution AVHRR data for weather studies. Some AVHRR data are available on CD-ROM. 


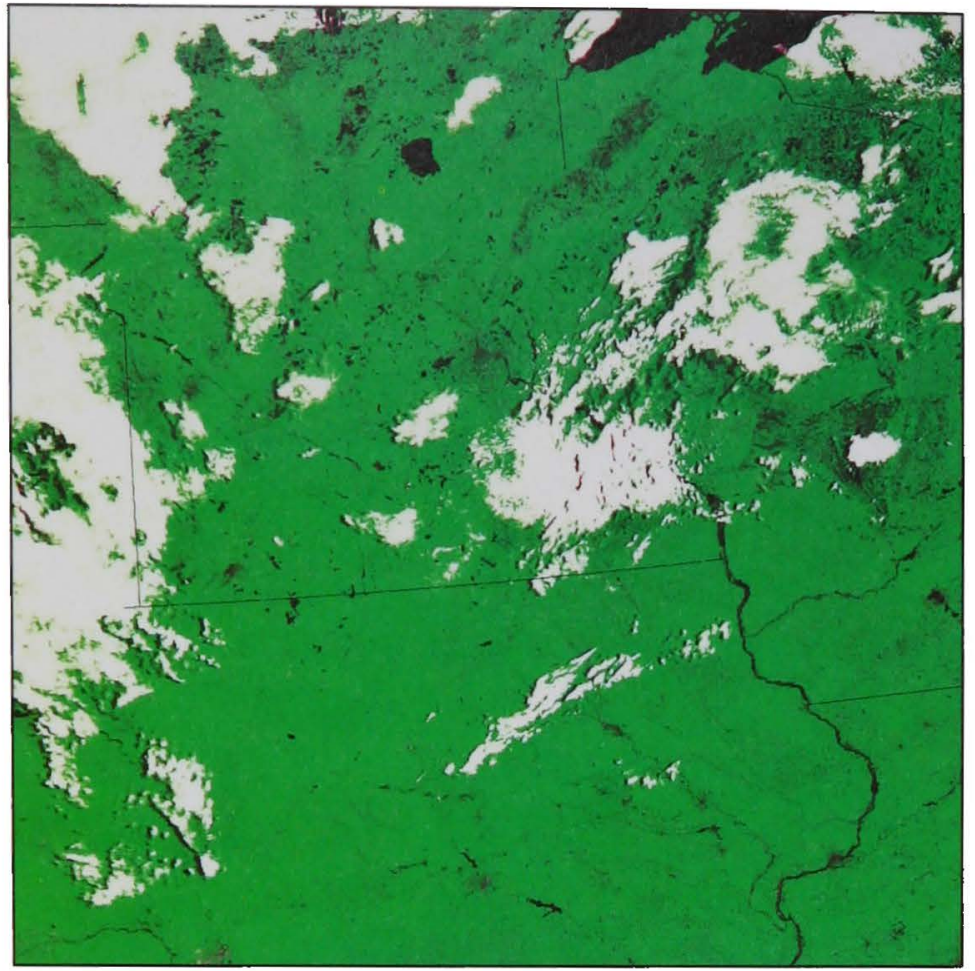

Figure 30a: Effects of flooding on the Mississippi River Basin AVHRR satellite data, July 17, 1992, and July 12, 1993

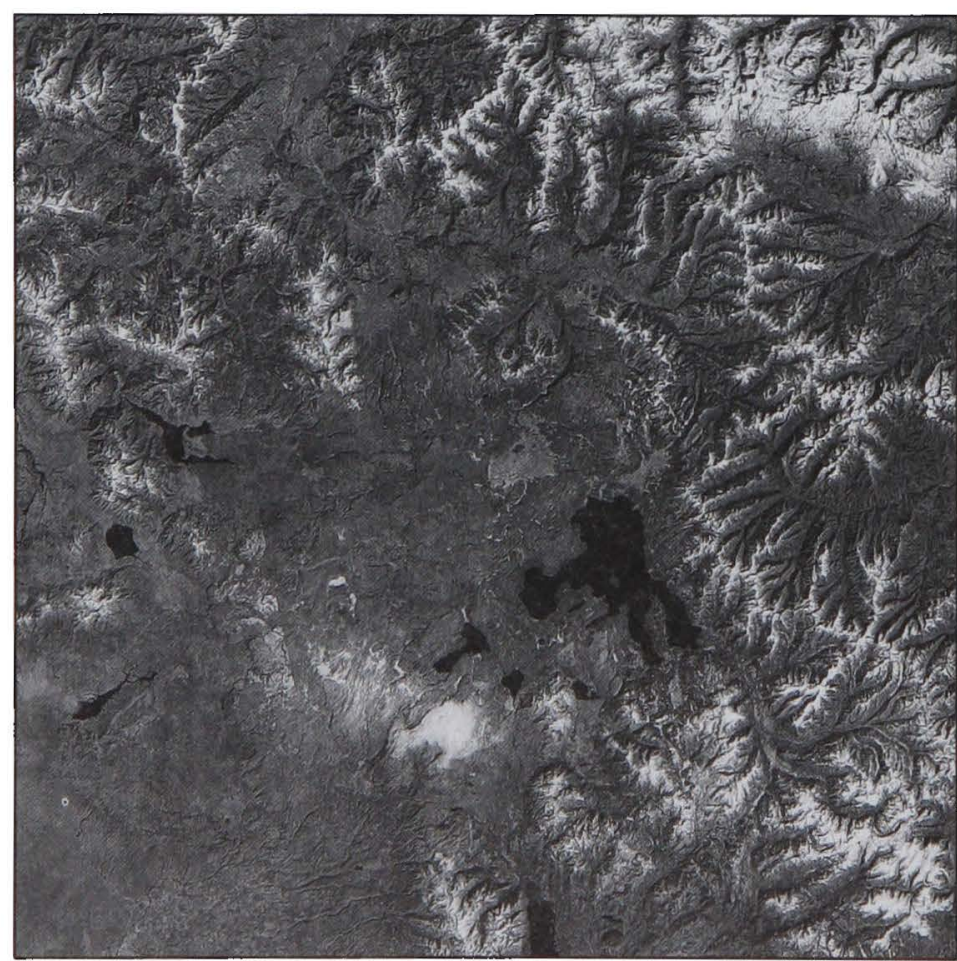

Figure 31a: Comparison of Landsat sensors: Yellowstone National Park, Wyo., Landsat multispectral scanner satellite image, October 1985, and Landsat thematic mapper satellite image, September 1993

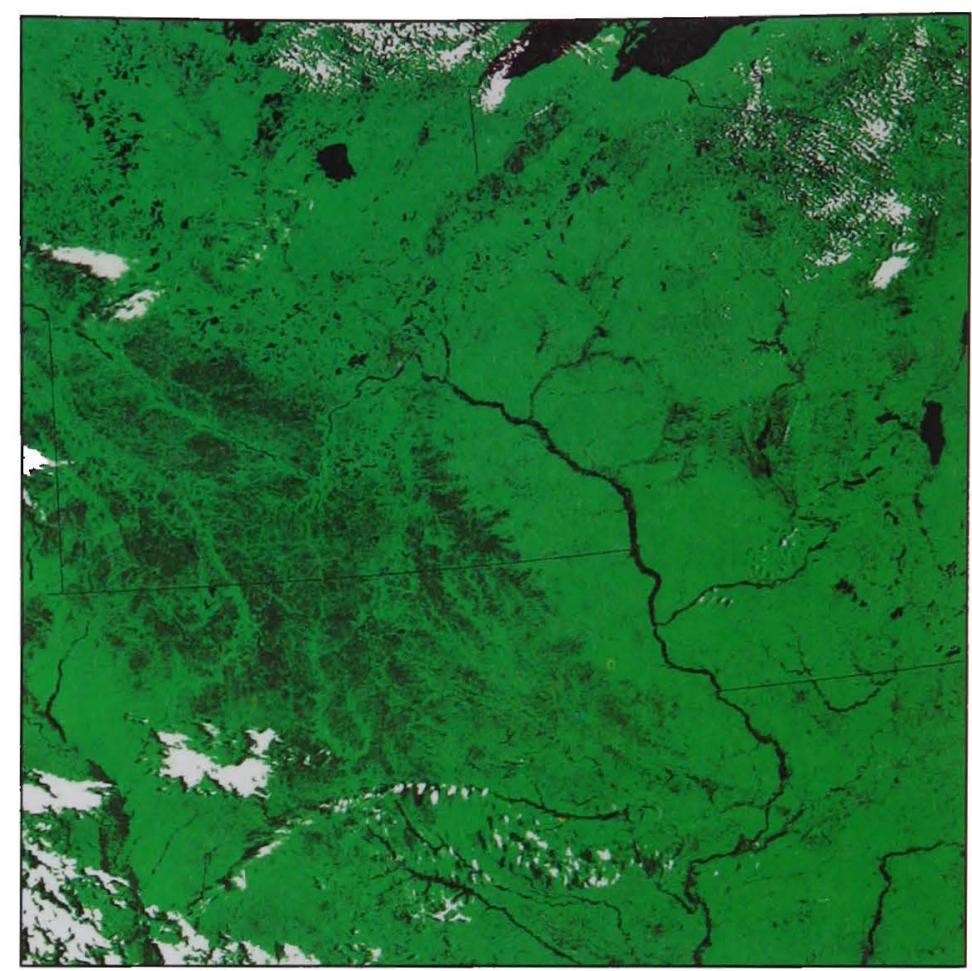

Figure 30b

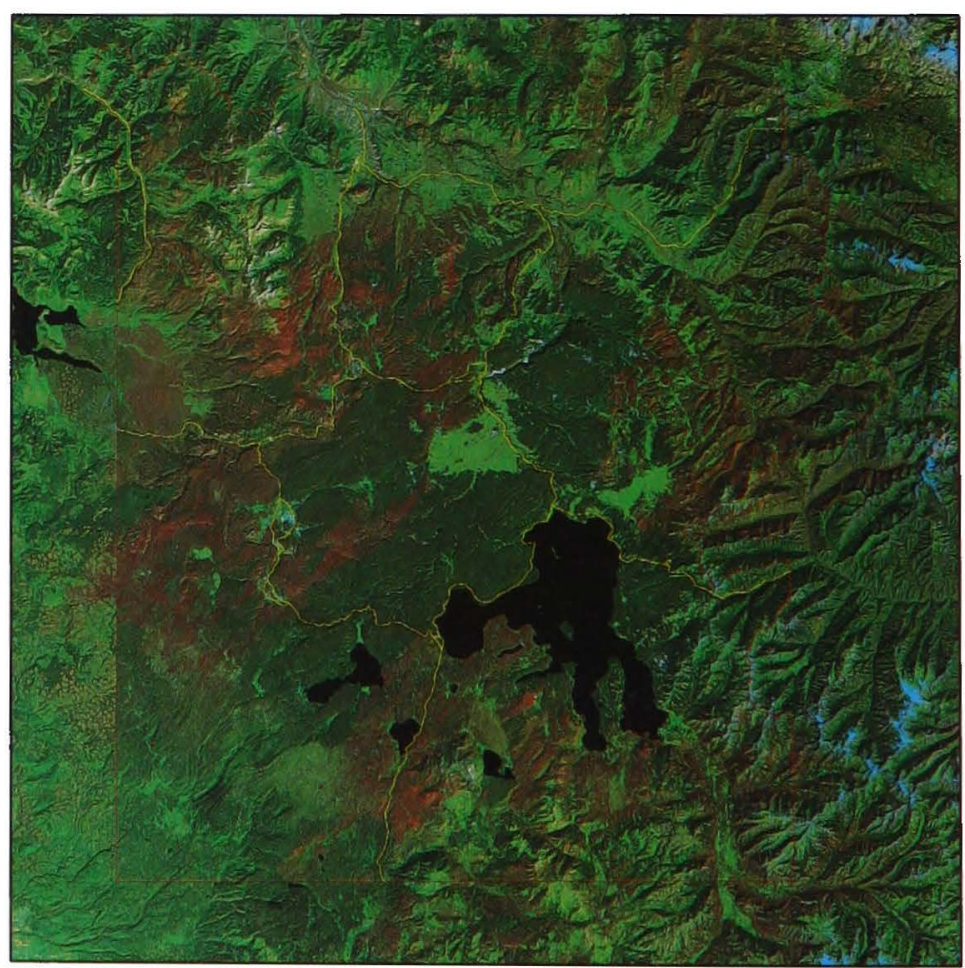

Figure 31b 


\section{Display Images}

The USGS has aerial photographs and images suitable for framing that can be ordered without custom research. In this category are satellite images and aircraft photographs of selected States, cities, regions, and features within the United States and of natural phenomena such as fires and volcanic eruptions. Some areas outside the United States are also covered. Some photographs taken on space missions by NASA astronauts are also available in this format.

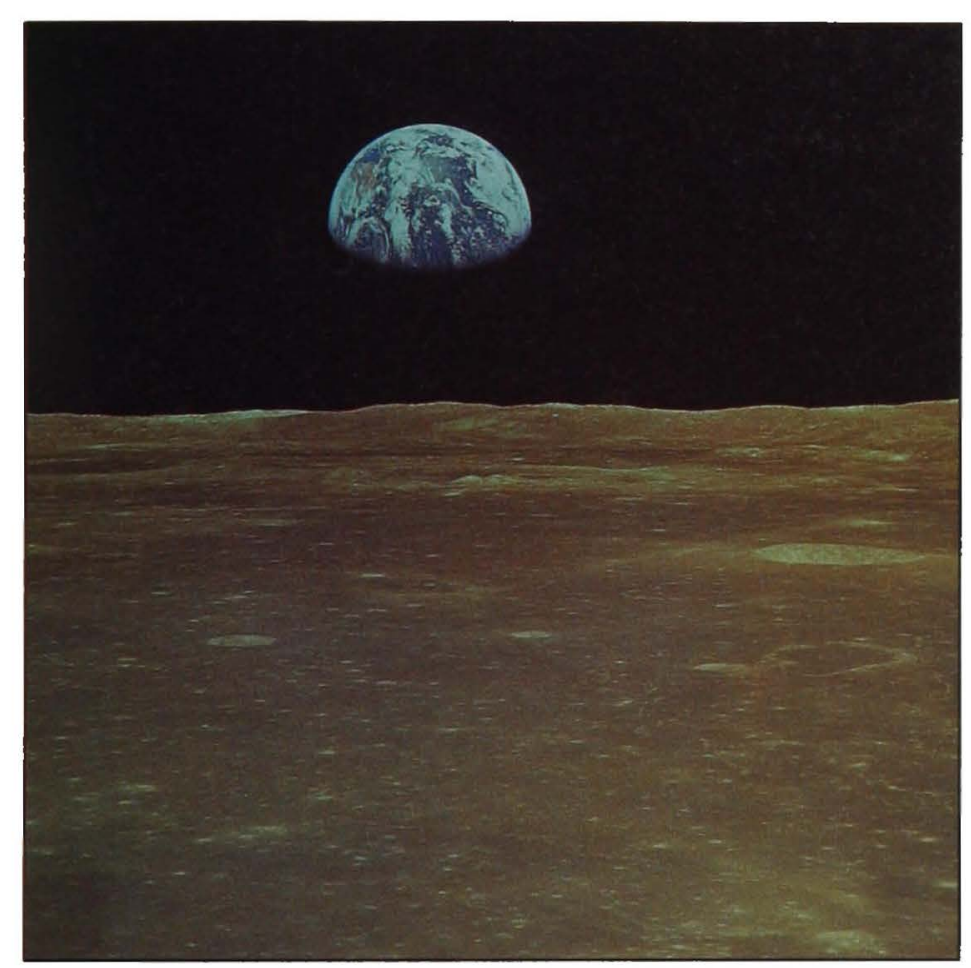

Figure 32: Earthrise from Moon, Apollo 11, July 1969

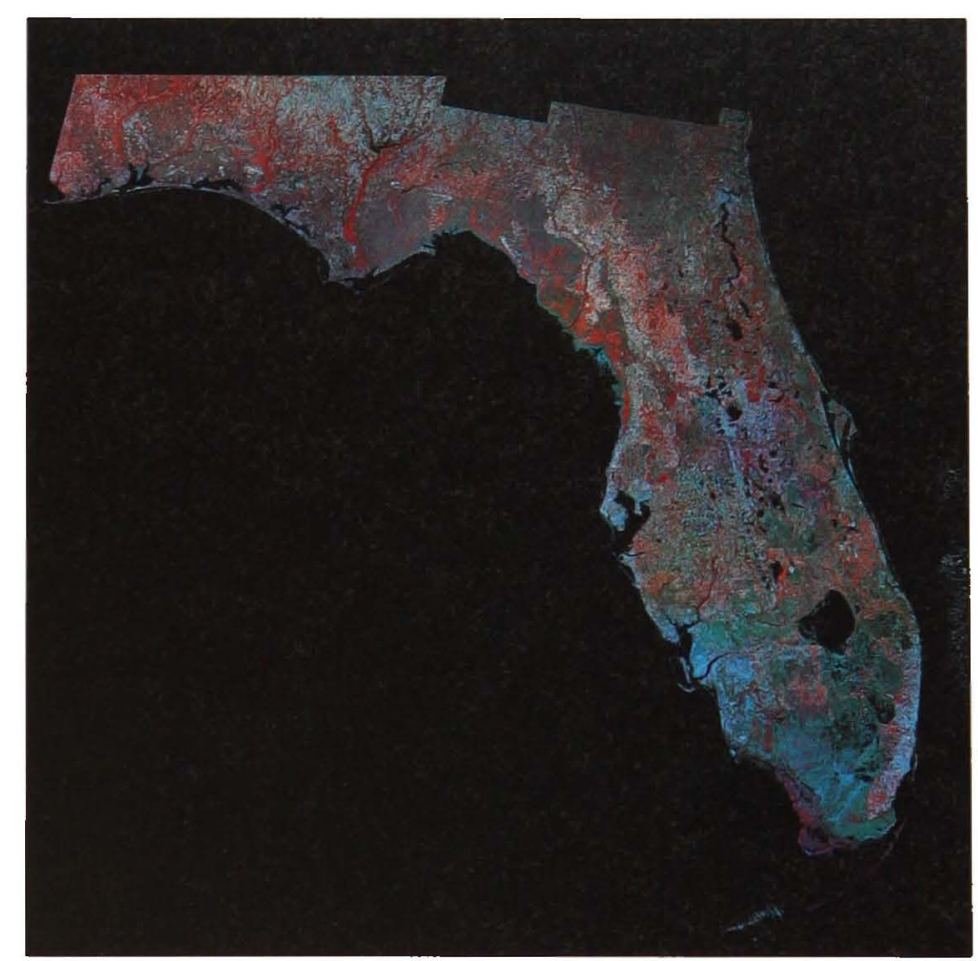

Figure 33: Florida, Landsat 5 multispectral scanner satellite image mosaic, April 1979 and May 1985 


\section{Ordering Information}

USGS aerial photographs covering the United States since the 1950's and worldwide satellite data from the early 1970's to the present can be ordered directly from the USGS. The USGS also has information about images available from other Government and State agencies and commercial sources. The World Wide Web Internet address for the USGS home page is <http://www.usgs.gov.>

\section{Satellite Imagery}

The USGS has produced a limited number of satellite image maps. For a list of these maps, call or write any Earth Science Information Center (ESIC) or call 1-800-USA-MAPS.

For worldwide satellite data information and ordering assistance, contact the USGS EROS Data Center's Customer Services at 605-594-6151; fax: 605-594-6589;

e-mail: custserv@edcmail.cr.usgs.gov; or write to Sioux Falls ESIC,

EROS Data Center,

Sioux Falls, SD 57198-0001.

Online information about satellite data is available on the Global Land Information System (GLIS), an interactive computer system that contains "metadata" or descriptive information about data sets of the Earth's land surface. GLIS is available via the Internet at <URL:http://edcwww.cr.usgs.gov/webglis/>.
For more information about GLIS, contact GLIS user assistance at 1-800-252-4547; e-mail: glis@glis.cr.usgs.gov; or write to USGS, EROS Data Center, GLIS User Assistance, Sioux Falls, SD 57198-0001.

\section{Aerial Photography}

The USGS ESIC's assist in identifying aerial photographs. The USGS produces the Aerial Photography Summary Record System (APSRS) CD-ROM that describes more than 600,000 aerial photography projects covering the United States and its territories. More than 600 Federal, State, and local agencies and commercial companies contribute to the APSRS CD-ROM database. The APSRS CD-ROM sells for $\$ 57.00$, plus a $\$ 3.50$ handling fee. To order the APSRS CD-ROM, or to request information on how to obtain a listing of photographs covering a specific area, contact any ESIC, or call 1-800-USA-MAPS.

The EARTHFAX fax-on-demand system is available 24 hours a day at 703-648-4888.

Telephone: 605-594-6151

Fax: 605-594-6589

e-mail: custserve@edcmail.cr.usgs.gov Mail: Customer Services, EROS Data Center, Sioux Falls, SD 57198-0001

World Wide Web: <http://edcwww/eroshome.html> 


\section{Scales and Ordering Identification Numbers for Illustrations in This Booklet}

The following list includes order identification numbers for most of the illustrations in this booklet. Prices are available from any Earth Science Information Center, most conveniently from Customer Services at the EROS Data Center, Sioux Falls, SD 57198, telephone 605-594-6151. Also listed are the scales of the aerial photography images ordered as 9-inch-square photographic products. (These are not necessarily the scales of images in the booklet, where they may have been enlarged or reduced for publication.)

Figure 1: (Front Cover), Original scale 1:40,000, 1 inch $=1.25$ miles, $1 \mathrm{~cm}=0.8 \mathrm{~km}$, NAPP Roll 1854, Frame 40

Figure 2: E-1827-99CT

Figure 3: E-1708-99CT

Figure 4: Original scale 1:58,000, 1 inch $=1.8$ miles, $1 \mathrm{~cm}=1.1 \mathrm{~km}$, NHAP 84 Roll 305 , Frame 32

Figure 5: E-1833-99CT

Figure 6: Original scale 1:40,000, 1 inch $=1.25$ miles, $1 \mathrm{~cm}=0.8 \mathrm{~km}$, NAPP Roll 1423 , Frame 96

Figure 7: Scale varies, E-1815-99CT

Figure 8: Original scale 1:40,000, 1 inch $=1.25$ miles, $1 \mathrm{~cm}=0.8 \mathrm{~km}$, NAPP Roll 4 , Frame 78

Figure 9: Original scale 1:58,000, 1 inch $=1.8$ miles, $1 \mathrm{~cm}=1.1 \mathrm{~km}$, NHAP 80 Roll 581 , Frame 27

Figure 10: $E-1488-99 C T$

Figure 11: Original scale $1: 40,000,1$ inch $=1.25$ miles, $1 \mathrm{~cm}=0.8 \mathrm{~km}$, NAPPB Roll 1840, Frame 170

Figure 12: Original scale 1:31,000, AB594004684ROLL, Frame 61, Right Half

Figure 13: Original scale $1: 40,000,1$ inch $=1.25$ miles, $1 \mathrm{~cm}=0.8 \mathrm{~km}$, NAPP Roll 1840, Frame 170
Figure 14: E-1702-99CT

Figure 15: Original scale $1: 40,000,1$ inch $=1.25$ miles, $1 \mathrm{~cm}=0.8 \mathrm{~km}$, NAPP Roll 511, Frame 159

Figure 16: Original scale 1:40,000, 1 inch $=1.25$ miles, $1 \mathrm{~cm}=0.8 \mathrm{~km}$, NAPPW Roll 6365, Frame 36

Figure 17: Original scale 1:58,000, 1 inch $=1.8$ miles, $1 \mathrm{~cm}=1.1 \mathrm{~km}$, NHAP 82 Roll 261, Frame 130

Figure 18: Original scale 1:80,000, 1 inch $=1.8$ miles, $1 \mathrm{~cm}=1.1 \mathrm{~km}$, NHAP 82 Roll 252, Frame 58

Figure 19: Original scale $1: 23,600,1$ inch $=.75$ mile, $1 \mathrm{~cm}=0.47 \mathrm{~km}$, GS-SA Roll 4, Frame 40

Figure 20: E-1804-99CT

Figure 21: Scale of quarter quadrangle 1:12,000, 1 inch $=0.6$ miles, $1 \mathrm{~cm}=0.4 \mathrm{~km}$

Figure 22: Scale: 1 inch $=15$ miles, $1 \mathrm{~cm}=9.5 \mathrm{~km}$, Sl1SSPA00820805

Figure 23: NAPPB Roll 7700, Frame 5

Figure 24: NAPPB Roll 7700, Frame 5

Figure 25: NAPPB Roll 7700, Frame 5

Figure 26: E-1469-99CT

Figure 27: E-1884-99CT

Figure 28: $1856-810 C T$

Figure 29: $\mathrm{E}-1879-88 \mathrm{CT}$

Figure 30a: E-1911-99CT

Figure 30b: E-1917-99CT

Figure 31a: This image was a custom product. Additional Landsat images of Yellowstone National Park are available as preselected Display Images.

Figure 31b: Y5349217291X0

Figure 32: $\mathrm{E}-1373-99 \mathrm{CT}$

Figure 33: E-1721-99CT 
U.S. Department of the Interior

U.S. Geological Survey

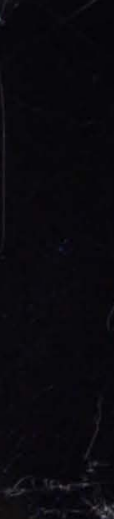

y

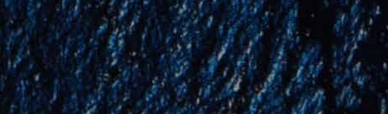

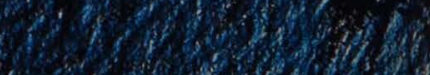

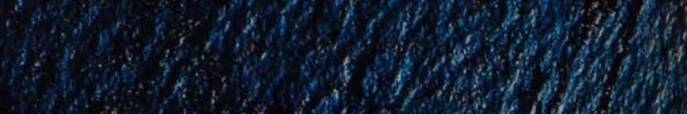

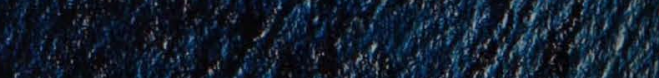

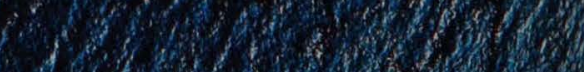

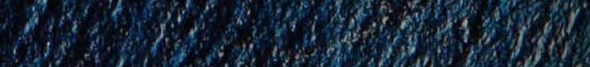
W

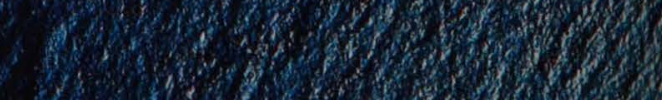

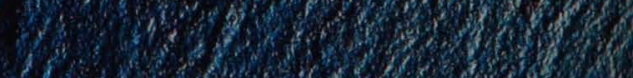

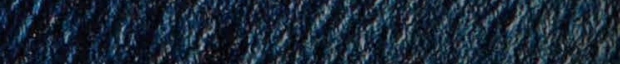

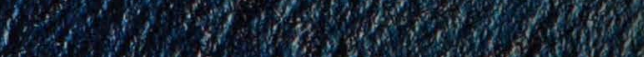

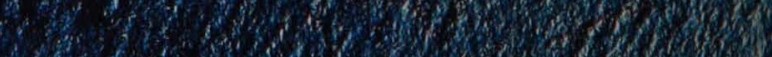

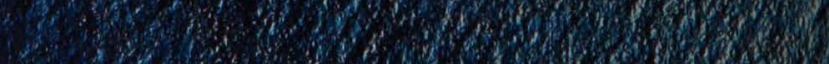

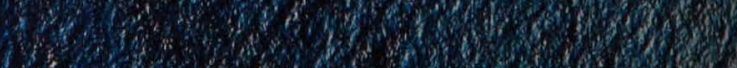

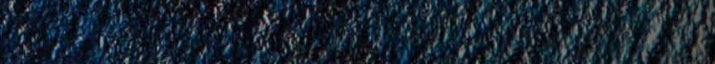

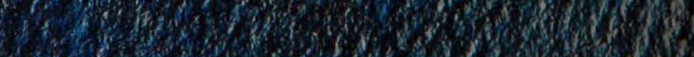

